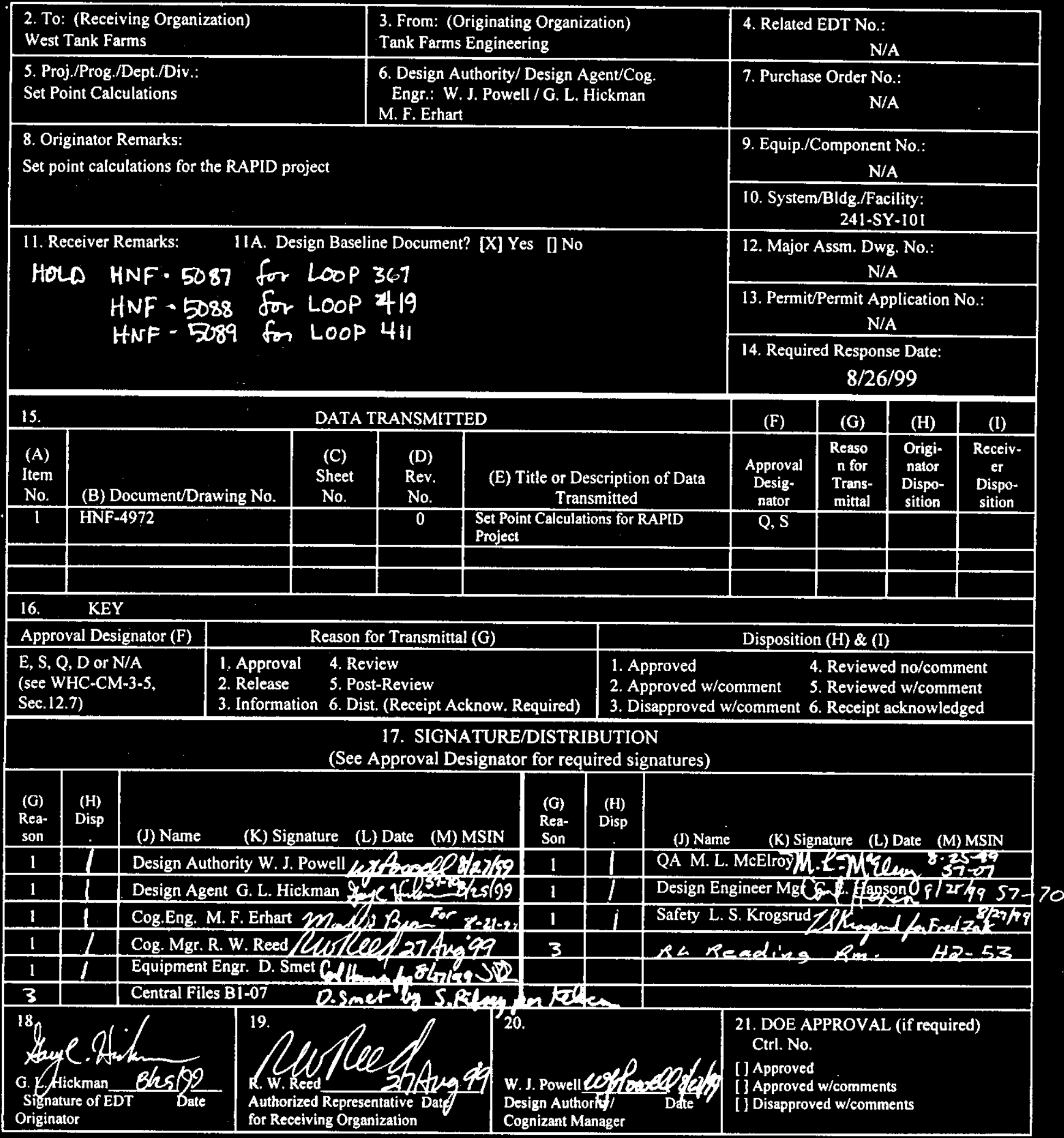

BD-7400-1 72-2 (05/96) GEF097 


\section{Set Point Calculations for RAPID Project}

G. I. HICKMAN, Floux Daniel Northwest, Inc.

for Lockheed Martin Hanford Company

Richland, WA 99352

U.S. Department of Energy Contract DE-AC06-96RL13200

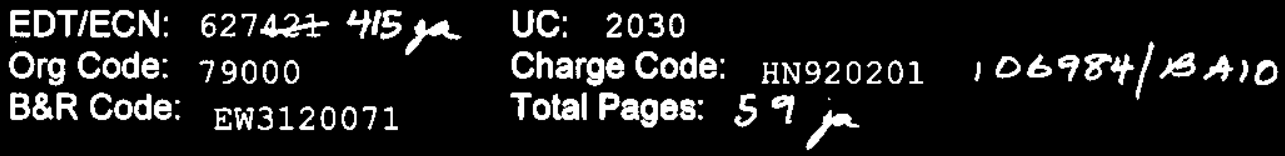

Key Words:

RAPID, waste transfer; SY Farm, 241-SY-101, Set Points, Set Range

\section{Abstract:}

The Respond and Pump in Days (RAPID) project was initiated to pump part of the contents of tank 241-SY-101 into tank 241-SY-102. This document establishes the basis for all set points and ranges used in the RAPID project.

TRADEMARK DISCLAMER. Roference herein to any apecilic commercial product, process, or service by trade name, trademark, manufacturer, or otherwise, does not necessarily constitute or imply its endorsement, recommendation, or favoring by the United States Covernmont or any acency thereof or its contractors or subcontractors.

Printed in the United States of America. To obtain copies of this document, contact: Document Control Services, P.O. Box 950, Mailstop H6-08, Richland WA 89352, Phone (509) 372-2420; Fax (509) 376-4989.

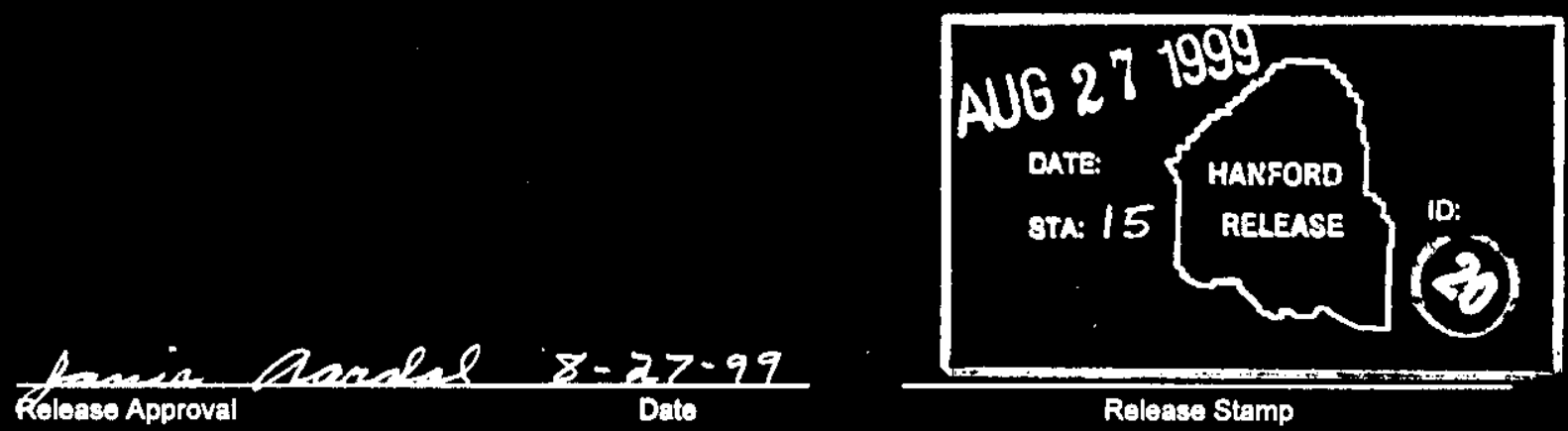




\section{SET POINT CALCULATIONS FOR RAPID PROJECT}

Revision 0 of this document is being released with several sections requiring additional technical review. These sections are clearly marked and information contained in them is for information only. These sections include flow loops 367 and 419, and temperature loop 411. This document will be revised upon completion of the technical review. 


\section{TABLE OF CONTENTS}

1.0 Introduction Page 01

2.0 Document ResultsPage 02

3.0 Setpoint Calculation Methodology Page 05

4.0 Loop Description and Setpoint Definition-

4.1 Current Loop Page 05

4.1.1 Loop 350Page 05

4.2 Flow Loops Page 05

4.2.1 Loop 367Page 07

4.2.2 Loop 418 Page 07

4.2.3 Loop 419 Page 12

4.3 Leak Detection Loops-

4.3.1 Loop 365 Page 12

4.3.2 Loop 366Page 19 Page 19

4.4 Level LoopPage 20

4.4.1 Loop 4164.5 Pressure Loops

4.5.1 Loop 3684.5.2 Loop 370Page 21 Page 21 Page 23 Page 23

4.5.3 Loop 371 4.5.4 Loop 417 Page 25 Page 26

4.5.5 Loop 420 Page 28 Page 31 4.6 Temperature Loops Page 32

4.6.1 Loop 369 Page 32

4.6.2 Loop 373 Page 37

4.6.3 Loop 401 Page 42

4.6.4 Loop 410 Page 42

4.6.5 Loop 411 Page 45

4.6.6 Loop 412 Page 47

4.6.7 Loop 413 Page 49

4.6.8 Loop 414 Page 51

4.6.9 Loop 415 Page 53

4.6.10 Loop HT1 Page 55

4.6.11 Loop HT2 Page 56

5.0 ReferencesPage 56 
HNF-4972, Rev 0

\section{SET POINT CALCULATIONS FOR THE RAPID PROJECT}

\subsection{INTRODUCTION}

There are 23 instrument and/or control loops utilized by the Respond and Pump in Days (RAPID) project. These range from the simple indication loop with two components to complex indication, control, and alarm loops with up to eight components. Several loops include safety class elements. This document is intended to describe the loops in full and to provide the basis for each of the element setpoints, ranges and accuracies identified in the RAPID project Master Equipment List (MEL). These values are developed in two steps. First, the base value is identified with reference to the supporting document providing that value. Second, a spreadsheet calculation is performed on each element and loop, utilizing a standard methodology described below, that takes into account known and suspected variance in output and establishes the actual setpoint used on a given element. The results of the spreadsheet are reported directly in this document.

This document is organized as follows. A summary of this document with all setpoints, ranges, and loop accuracy is given in Section 2. Section 3 has a detailed explanation of the methodology for determining the setpoint and allowable value for each element and/or loop. This is followed by a detailed description of each loop, including the way an error provided by any given element cascades through the rest of the loop. Within each loop section, the base value for the setpoint is defined and the results of the setpoint and allowable limit calculation are given.

\subsection{DOCUMENT RESULTS}

Values calculated and presented in this document are based on the best available information during the design phase of this project. It is recognized that system testing and actual transfers will likely result in the need to adjust some of the values given.

\begin{tabular}{|c|c|c|c|c|c|}
\hline Tag/AIN & Set Range & Set Point & $\begin{array}{l}\text { Calibration } \\
\text { Tolerance }\end{array}$ & $\begin{array}{l}\text { Display } \\
\text { Accuracy } \\
\text { (Absolute) } \\
\end{array}$ & $\begin{array}{c}\text { Display } \\
\text { Accuracy ( } \% \text { of } \\
\text { full scale) }\end{array}$ \\
\hline SY272-WT-VFD-350 & $0-130 \mathrm{~A}$ & N/A & $\mathrm{N} / \mathrm{A}$ & N/A & $\bar{N} / \mathrm{A}$ \\
\hline SY461-WT-11-350 & $0-130 A$ & N/A & $4 \%$ & $+/-5.24 \mathrm{~A}$ & $+/ .4 .0 \%$ \\
\hline SY101-WT-FE-367 & $0-310$ GPM & N/A & (1) & N/A & N/A \\
\hline SY101-WT-FOT-367 (2) & $0-310 \mathrm{GPM}$ & $\mathbf{N} / \mathbf{A}$ & $1.00 \%$ & $\begin{array}{l}+/-3.47 \text { GPM } \\
\text { (4) }\end{array}$ & $+/-1.12 \%$ \\
\hline SY101-WT-FQIT-367 (3) & $0-1019$ Gat & S.7. & $1.00 \%$ & N/A & $+/-1.12 \%(5)$ \\
\hline SY101-WT-FI-367A & 0-310 GPM & W/A & $1.00 \%$ & $\begin{array}{l}+/-8.56 \mathrm{GPM} \\
\text { (4) }\end{array}$ & $+/-7.13 \%(4)$ \\
\hline SY461-WT-FI-367B & $0-310$ GPM & NA & N/A & N/A & N/A \\
\hline SY461-WT-F01 867 & $0-1019 \mathrm{Gal}$ & E & N/A & $\mathrm{N} / \mathrm{A}$ & N/A \\
\hline \multicolumn{6}{|c|}{ For information only, pending completion of kedinloal review. } \\
\hline \multirow{2}{*}{\multicolumn{6}{|c|}{$\begin{array}{l}\text { (1) The element is integral to the transmitter. Calibration and accuracy are dealt with on the transmitter. } \\
\text { (2) As a flow rate. }\end{array}$}} \\
\hline & & & & & \\
\hline \multicolumn{6}{|l|}{$\begin{array}{l}\text { (2) As a flow rate. } \\
\text { (3) As a flow total. }\end{array}$} \\
\hline \multicolumn{6}{|c|}{ (4) Accuracy rating assumes flow rate above $20 \%$ of full scale. } \\
\hline \multicolumn{6}{|c|}{$\begin{array}{l}\text { (5) Reading accuracy assumes flow rate above } 20 \% \text { of full scale and is listed as a percent of flow, not \% } \\
\text { of full scale. }\end{array}$} \\
\hline
\end{tabular}




\begin{tabular}{|c|c|c|c|c|c|}
\hline Tag/EIN & Set Range & Set Point & $\begin{array}{l}\text { Calibration } \\
\text { Tolerance }\end{array}$ & $\begin{array}{c}\text { Display } \\
\text { Accuracy } \\
\text { (Absolute) }\end{array}$ & $\begin{array}{c}\text { Display } \\
\text { Accuracy ( } \% \text { of } \\
\text { full scale) }\end{array}$ \\
\hline \multicolumn{6}{|c|}{ Continued from previous page } \\
\hline POR32-RW-FE-418 & $0-30 \mathrm{ft} / \mathrm{s}$ & N/A & (1) & $\mathrm{N} / \mathrm{A}$ & $\mathrm{N} / \mathrm{A}$ \\
\hline POR32-RW-FQIT-418 (2) & $0-273$ GPM & $\mathrm{N} / \mathrm{A}$ & $\mathrm{N} / \mathrm{A}$ & $\mathrm{N} / \mathrm{A}$ & $\mathrm{N} / \mathrm{A}$ \\
\hline POR32-RW-FQIT-418 (3) & $0-10^{\wedge} \mathrm{g}$ Gal. & $\mathrm{N} / \mathrm{A}$ & N/A & N/A & $\mathrm{N} / \mathrm{A}$ \\
\hline POR32-RW-FI-418 & $0-273$ GPM & N/A & N/A & N/A & $\mathrm{N} / \mathrm{A}$ \\
\hline POR32-RW-FQI-418 & $0-10^{\wedge 9}$ Gal. & N/A & N/A & N/A & N/A \\
\hline POR32-RW-FE-419 & $0-30 \mathrm{ft} / \mathrm{s}$ & N/A & (1) & N/A & N/A \\
\hline POA32-RW-FQIT-419 (2) & $0-273$ GPM & $\mathrm{N} / \mathrm{A}$ & $1 \%(8)$ & $+/-2.81 \mathrm{GPM}$ & $+/-4.68 \%(10)$ \\
\hline POA32-RW-FQIT-419 (3) & 0-1019 Gal. & NA & $1 \%(\theta)$ & $\mathrm{N} / \mathrm{A}$ & $+/ .1 .16 \%$ \\
\hline SY101-WT-FI-419 & $0-273$ GPM & N/A & $1 \%(8)$ & $+1-8.15 \mathrm{GPM}$ & $+t-13.58 \%(10)$ \\
\hline SY461-RW-FIY-419(4) & $0-273$ GPM & N/A & $1 \%(8)$ & $+1-3.92 \mathrm{GPM}$ & $+/-6.53 \%(10)$ \\
\hline SY401-RW-FIY-419 (5) & N/A & $65.08 \mathrm{gpm}$ & $1 \%(8)$ & $N / A$ & N/A \\
\hline SY461-RW-FIY-419(6) & N/A & $24.92 \mathrm{gpm}$ & $1 \%(8)$ & NA & N/A \\
\hline SY461-RW-FAH-419 (5) & $\mathbf{N} / \mathbf{A}$ & $=\mathrm{NA}$ & N/A & $\mathbf{N} / \mathbf{A}$ & N/A \\
\hline SY461-AW-FAL-419(6) & $\mathbf{N} / \mathbf{A}$ & HN/A & N/A & $\mathbf{N} / \mathbf{A}$ & N/A \\
\hline \multicolumn{6}{|c|}{ For information only, pending completion of tachincal review. } \\
\hline SY101-WT-LDE-365 & N/A & $5 / 8^{\prime \prime}$ & $\mathrm{N} / \mathrm{A}$ & N/A & N/A \\
\hline SY101-WT-LDSTA-365 & N/A & $10 \mathrm{k} \mathrm{ohm}$ & N/A & N/A & N/A \\
\hline LDK-365 (7) & N/A & N/A & N/A & N/A & N/A \\
\hline SY101-WT-LDA-365A (7) & N/A & $\mathrm{N} / \mathrm{A}$ & $\mathrm{N} / \mathrm{A}$ & N/A & $\mathrm{N} / \mathrm{A}$ \\
\hline SY461-WT-LDA-365B (7) & $\mathrm{N} / \mathrm{A}$ & $\mathrm{N} / \mathrm{A}$ & N/A & $\mathrm{N} / \mathrm{A}$ & N/A \\
\hline SY101-WT-LDE-366 & N/A & $1 / 2^{11}$ & N/A & N/A & N/A \\
\hline SY101-WT-LDSTA-366 & N/A & $10 \mathrm{k} \mathrm{ohm}$ & N/A & N/A & N/A \\
\hline LDK-366 (7) & N/A & $\mathrm{N} / \mathrm{A}$ & $\mathrm{N} / \mathrm{A}$ & N/A & N/A \\
\hline SY101-WT-LDA-366A (7) & N/A & N/A & N/A & N/A & N/A \\
\hline SY461-WT-LDA-366B (7) & $\mathrm{N} / \mathrm{A}$ & N/A & $\mathrm{N} / \mathrm{A}$ & N/A & N/A \\
\hline \multicolumn{6}{|c|}{ (1) The element is integral to the transmitter. Calibration and accuracy are dealt with on the transmitter. } \\
\hline \multicolumn{6}{|l|}{ (2) As a flow rate. } \\
\hline \multicolumn{6}{|l|}{ (3) As a flow total. } \\
\hline \multirow{2}{*}{\multicolumn{6}{|c|}{ (4) As a flow indicator }} \\
\hline & & & & \multicolumn{2}{|c|}{ (5) As a high flow switch } \\
\hline \multicolumn{6}{|l|}{ (6) As a low flow switch } \\
\hline \multicolumn{6}{|c|}{$\begin{array}{l}\text { (7) Leak Detector Alarms are triggered by resistance between the electrodes dropping below } 10 \mathrm{k} \text { ohm. } \\
\text { Any liquid waste reaching both electrodes would drop the resistance below the trigger point, causing the } \\
\text { alarms to annunciate. }\end{array}$} \\
\hline \multicolumn{6}{|c|}{ (8) Tolerance is $1 \%$ of full scale when flow is above $20 \%$ of full scale. } \\
\hline \multicolumn{6}{|c|}{ (9) Tolerance is $1 \%$ of reading } \\
\hline \multicolumn{6}{|l|}{$(10) \%$ of reading at $60 \mathrm{gpm}$. } \\
\hline
\end{tabular}




\begin{tabular}{|c|c|c|c|c|c|}
\hline Tag/EIN & Set Range & Set Point & $\begin{array}{l}\text { Calibration } \\
\text { Tolerance }\end{array}$ & $\begin{array}{c}\text { Display } \\
\text { Accuracy } \\
\text { (Absolute) }\end{array}$ & $\begin{array}{c}\text { Display } \\
\text { Accuracy ( } \% \text { of } \\
\text { full scale) }\end{array}$ \\
\hline \multicolumn{6}{|c|}{ Continued from previous page } \\
\hline POR32-RW-LE-416 (1) & N/A & N/A & N/A & N/A & N/A \\
\hline $\begin{array}{l}\text { POR32-RW-LAHH-416 } \\
\text { (1) }\end{array}$ & N/A & $74^{\prime \prime}$ & N/A & $\mathrm{N} / \mathrm{A}$ & N/A \\
\hline POR32-RW-LAH-416 (1) & $\mathrm{N} / \mathrm{A}$ & $64^{\prime \prime}$ & N/A & N/A & $\mathrm{N} / \mathrm{A}$ \\
\hline POR32-RW-LAL-416 (1) & $\mathrm{N} / \mathrm{A}$ & $36^{\prime \prime}$ & N/A & N/A & N/A \\
\hline POR32-RW-LALL-416 (1) & N/A & $30^{\prime \prime}$ & N/A & N/A & N/A \\
\hline SY101-WT-PE-368 & N/A & $\mathrm{N} / \mathrm{A}$ & N/A & NA (5) & $\mathrm{N} / \mathrm{A}$ \\
\hline SY101-WT-PI-368 & $0-100$ psig & N/A & $5 \%(2)$ & $+/-5$ psig & $+/-12.5 \%$ \\
\hline SY101-WT-PS-370 & N/A & 15 psig & $5 \%(3)$ & N/A & NA \\
\hline SY101-WT-PAH-370A & $\mathrm{N} / \mathrm{A}$ & N/A & N/A & N/A & NA \\
\hline SY461-WT-PAH-370B & N/A & N/A & N/A & N/A & NA \\
\hline SY101-WT-PS-371 & N/A & 15 psig & $5 \%(3)$ & N/A & NA \\
\hline SY101-WT-PAH-371A & N/A & N/A & N/A & N/A & NA \\
\hline SY461-WT-PAH-371B & N/A & $\mathrm{N} / \mathrm{A}$ & N/A & $\mathrm{N} / \mathrm{A}$ & NA \\
\hline POR32-RW-PIT-417 & $0-250$ psig & N/A & $5 \%(2)$ & $+/-12.51$ psig & $+/-6.25 \%(4)$ \\
\hline POR32-RW-PI-417 & $0-250$ psig & N/A & $5 \%(2)$ & $+/-17.97$ psig & $+/-8.99 \%(4)$ \\
\hline POR32-RW-PE-420 & NA & $\mathrm{N} / \mathrm{A}$ & $\mathrm{N} / \mathrm{A}$ & N/A (5) & N/A \\
\hline SY101-WT-PI-420 & $0-250$ psig & $N / A$ & $\mathrm{~N} / \mathrm{A}$ & $+/-12.5$ psig & $+/-6.25 \%(4)$ \\
\hline SY101-WT-TE-369 & N/A & N/A & N/A & N/A & $\bar{N} / \mathrm{A}$ \\
\hline SY101-WT-TT-369 & $32-212 F$ & $\mathrm{~N} / \mathrm{A}$ & $1 \%(2)$ & N/A & N/A \\
\hline SY101-WT-TI-369A & $32-212 \mathrm{~F}$ & $\mathrm{~N} / \mathrm{A}$ & $1 \%(2)$ & $+/-7.76 \mathrm{~F}$ & $+/-5.96 \%(6)$ \\
\hline SY461-WT-TI-369B & $32-212 F$ & N/A & $1 \%(2)$ & $+/-3.05 F$ & $+/-2.35 \%(6)$ \\
\hline \multicolumn{6}{|c|}{ (1) The level element has four independent trip points, set at the values shown for the alarms. } \\
\hline \multicolumn{6}{|l|}{ (2) As a percent of full scale } \\
\hline \multicolumn{6}{|l|}{ (3) As a percent of setpoint } \\
\hline \multicolumn{6}{|c|}{\begin{tabular}{|l|l} 
(4) At 200 psig & \\
\end{tabular}} \\
\hline \multirow{2}{*}{\multicolumn{6}{|c|}{$\begin{array}{l}\text { (5) Calibrated with the pressure indicator. Calibration tolerance is incorporated in the pressure indicator. } \\
\text { (6) At } 130 \mathrm{~F}\end{array}$}} \\
\hline & & & & & \\
\hline \multicolumn{6}{|c|}{ Continued on following page } \\
\hline
\end{tabular}




\begin{tabular}{|c|c|c|c|c|c|}
\hline Tag/EIN & Set Range & Set Point & $\begin{array}{l}\text { Calibration } \\
\text { Tolerance }\end{array}$ & $\begin{array}{c}\text { Display } \\
\text { Accuracy } \\
\text { (Absolute) }\end{array}$ & $\begin{array}{c}\text { Display } \\
\text { Accuracy (\% of } \\
\text { full scale) }\end{array}$ \\
\hline \multicolumn{6}{|c|}{ Continued from previous page } \\
\hline & & & & & \\
\hline SY101-WT-TE-373 & N/A & $\mathrm{N} / \mathrm{A}$ & $\mathrm{N} / \mathrm{A}$ & N/A & N/A \\
\hline SY101-WT-TT-373 & $32-212 F$ & N/A & $1 \%(1)$ & N/A & N/A \\
\hline SY101-WT-TI-373 & $32-212 F$ & N/A & $1 \%(1)$ & $+/ \cdot 7.76 \mathrm{~F}$ & $+/-5.97 \%(2)$ \\
\hline SY461-RW-TIY-373 & $32-212 F$ & $\mathrm{~N} / \mathrm{A}$ & $1 \%(1)$ & $+/-3.06 \mathrm{~F}$ & $+/-2.35 \%(2)$ \\
\hline SY101-WT-TAL-373A & N/A & $114 \mathrm{~F}$ & N/A & $\mathrm{N} / \mathrm{A}$ & N/A \\
\hline SY101-WT-TAL-373B & N/A & $114 \mathrm{~F}$ & $\mathrm{~N} / \mathrm{A}$ & N/A & N/A \\
\hline POR32-RW-TC-401 & N/A & N/A & N/A (3) & N/A & N/A \\
\hline POR32-RW-AC-401 & N/A & N/A & $\mathrm{N} / \mathrm{A}(3)$ & N/A & N/A \\
\hline POR32-RW-TE-410 & N/A & N/A & N/A & N/A & N/A \\
\hline POR32-RW-TIC-410 & $32-212 F$ & $126 \mathrm{~F}$ & $5 \%(4)$ & $+/-27.7 \mathrm{~F}$ & $+/-21.31 \%(2)$ \\
\hline POR32-RW-TE-411A & N/A & N/A & N/A & $\mathbf{N} / \mathbf{A}$ & $\mathbf{N} / \mathbf{A}$ \\
\hline POR32-AW-TE-411B & N/A & N/A & N/A & $\mathbf{N} / \mathbf{A}$ & N/A \\
\hline POR32-RW-TC-411 & 32-212F & $\begin{array}{l}\text { Control } \\
\text { Point = } \\
126 F \\
\text { Shut Off = } \\
\text { 134F }\end{array}$ & $5 \%(4)$ & N/A & $\mathbf{N} / \mathbf{A}$ \\
\hline \multicolumn{6}{|c|}{ For information only, pending completion of toch nical review. } \\
\hline POR32-RW-TE-412 & N/A & N/A & N/A & N/A & $\mathrm{N} / \mathrm{A}$ \\
\hline POR32-RW-TI-412 & $0-130 A$ & N/A & $5 \%(4)$ & $+/-27.7 F$ & $+/-21.31 \%(2)$ \\
\hline POR32-RW-TE-413 & N/A & N/A & $N / A$ & N/A & N/A \\
\hline POR32-RW-TIC-413 & $32-212 F$ & $126 \mathrm{~F}$ & $5 \%(4)$ & $+/-27.7 \mathrm{~F}$ & $+/-21.31 \%(2)$ \\
\hline POR32-RW-TE-414 & N/A & N/A & N/A & N/A & N/A \\
\hline POR32-RW-TIC-414 & $32-212 \mathrm{~F}$ & $126 \mathrm{~F}$ & $5 \%(4)$ & $+/-27.7 \mathrm{~F}$ & $+/-21.31 \%(2)$ \\
\hline POR32-RW-TE-415 & N/A & N/A & N/A & N/A & N/A \\
\hline POR32-RW-TIC-415 & $32-212 F$ & $126 \mathrm{~F}$ & $5 \%(4)$ & $+/-27.7 F$ & $+/-21.31 \%(2)$ \\
\hline TS-HT1 & N/A & $130 \mathrm{~F}$ & N/A (3) & N/A & N/A \\
\hline TS-HT2 & N/A & 130F & N/A (3) & N/A & N/A \\
\hline & & & & & \\
\hline \multicolumn{6}{|c|}{ (1) As a percent of full scale } \\
\hline \multicolumn{6}{|l|}{ (2) At $130 \mathrm{~F}$} \\
\hline \multicolumn{6}{|c|}{ (3) Factory calibrated, will not be field calibrated. } \\
\hline \multicolumn{6}{|l|}{ (4) As percent of span } \\
\hline
\end{tabular}




\subsection{SETPOINT CALCULATION METHODOLOGY}

The primary basis for the methodology used in this document is a draft instruction for instrument setpoint calculation provided by Equipment Engineering. It is based on ANSI/SA-S67.04-Part I-1994, "Setpoints for Nuclear Safety-Related Instrumentation."

The first step is to identify and quantify each of the various uncertainties associated with each element in an instrument loop or channel. These may include reference accuracy, temperature effect, radiation effect, seismic effect, humidity effect, calibration uncertainty, power supply effect, and drift. From these values, two calculations are performed on each element. The first creates an accuracy value for each element and is composed of a square root of the sum of the squares calculation. The second is a drift calculation, which is simply the manufacturers drift value in percent of the upper range limit (URL) multiplied by the URL divided by the span. This value is multiplied by the expected time interval for the instrument to be used divided by the manufacturers time interval. These two calculations provide the element accuracy and drift for any given element. It should be noted that most instruments used in this system have no measurable drift. This is because they are either solid state devices or items that do not drift. The effect of drift is only calculated for those instruments with published drift data.

From the above values, a channel or loop drift can be calculated using a square root of the sum of the squares methodology. Loop accuracy is similarly defined as the square root of the sum of squares of the loop elements, plus the combined element bias. The total channel or loop uncertainty is then the square root of the sum of the squares of the channel accuracy and drift, plus the total bias. From this value the trip setpoint is found by adding the base alarm or control setpoint with the channel uncertainty and the margin. The allowable value is found by adding the trip setpoint with the channel uncertainty.

\subsection{LOOP DESCRIPTION AND SETPOINT DEFINITION}

\subsection{CURRENT LOOP}

\subsubsection{LOOP 350}

\section{LOOP DESCRIPTION}

This is a simple indication loop composed of the sensing element and an indicator. The sensing element in this system is SY272-WT-VFD-350, which sends a $4-20 \mathrm{~mA}$ signal proportional to the motor current to SY461-WT-II-350. SY461-WT-II-350 converts the 4-20mA signal into a digital display of 0-130A.

\section{SETPOINT BASIS}

The motor is capable of drawing between 0 and $120 \mathrm{~A}$. The indication on SY461-WT-II-350 is intended for diagnostic purposes only and qualitative values will be sufficient. As such, a display accuracy of $\pm 5 \%$ is considered sufficient.

\section{SETPOINT VALUES}

The primary consideration is that the current level used by the transfer pump SY 101-WT-P-350 is correctly displayed on SY461-WT-II-350. As such, the 4-20mA input to SY461-WT-II-350 has been set to display 0-130A which envelops the expected amperage draw of SY 101-WT-P-350. 
The accuracy of the SY272-WT-VFD-350 is derived below:

\begin{tabular}{|c|c|c|c|}
\hline \multirow[t]{3}{*}{ VFD-350 ACCURACY } & & Robicon & ID-PWM454GT, $125 \mathrm{hP}$ \\
\hline & \multicolumn{2}{|c|}{ Common Unit Value, Amps } & Source/Reason \\
\hline & Random & Blas & \\
\hline Reference Uncertainty & 0.13 & & $\begin{array}{l}\text { Based on a phone call with Koley } \\
\text { Engineered Products, Inc., the accuracy } \\
\text { of the } 4-20 \mathrm{~mA} \text { output is } 10 \text { bit accuracy } \\
(.1 \%) \text {. Output range is } 4-20 \mathrm{~mA} \text { for } 0- \\
130 \mathrm{~A} \text { draw on the pump. } .1 \% \text { of } 130 \mathrm{~A} \text { is } \\
.13 \mathrm{~A}\end{array}$ \\
\hline Temperature Bffect & 0.00 & & $\begin{array}{l}\text { Temperature in the cabinet is within the } \\
\text { limits of the VFD (0-40C ambient), no } \\
\text { effect. }\end{array}$ \\
\hline Radiation Bffect & 0 & & VFD is in a low radiation environment \\
\hline Seismic/Vibratlon & 0 & & $\begin{array}{l}\text { System is shut down on seismic events, } \\
\text { no impact. }\end{array}$ \\
\hline Humidity Effect & 0 & & $\begin{array}{l}\text { Allowable humidity is } 95 \% \text {, non } \\
\text { condensing. The MCC is a low humidity } \\
\text { environment. }\end{array}$ \\
\hline Calibration Uncertainty & 0.65 & & $\begin{array}{l}\text { Device will not be calibrated. Factory } \\
\text { calibration is assumed to be within .5\% }\end{array}$ \\
\hline Power Supply Effect & 0 & & $\begin{array}{l}\text { VFD requires } 460 / 480 \mathrm{VAC}+/-10 \% \text {. No } \\
\text { effect. }\end{array}$ \\
\hline Element Accuracy & 0.66 & 0 & \\
\hline
\end{tabular}


The accuracy of SY461-WT-II-350 is derived below:

\begin{tabular}{|c|c|c|c|}
\hline II-350 ACCURACY & & $\begin{array}{c}\text { Newport } \\
\text { Electronics }\end{array}$ & INFP-0210-C2 \\
\hline & \multicolumn{2}{|c|}{ Common Unit Value, Amps } & Source/Reason \\
\hline & Random & Bias & \\
\hline Reference Uncertainty & 0.0065 & & $\begin{array}{l}.005 \% \text { of reading. Maximum value of } \\
130 \mathrm{~A} \text { used. }\end{array}$ \\
\hline Temperature Effect & 0.00 & & $\begin{array}{l}\text { The accuracy is based on a } 25 \mathrm{C} \\
\text { temperature. Span error is } 20 \mathrm{ppm} / \mathrm{C} \text {. } \\
\text { The } 350 \mathrm{~B} \text { panel is assumed to have a } \\
\text { maximum temperature of } 92 \mathrm{~F} \text {, or } 8.33 \mathrm{C} \\
\text { above } 25 \mathrm{C} \text {. The error is expected to be } \\
\text { no greater than } 0.0002 \mathrm{~A}\end{array}$ \\
\hline Radiation Effect & 0 & & $\begin{array}{l}\text { DACs is a low radiation environment, no } \\
\text { effect anticipated. }\end{array}$ \\
\hline Seismic/Vibration & 0 & & $\begin{array}{l}\text { System is shut down on seismic events, } \\
\text { no impact. }\end{array}$ \\
\hline Humidity Effect & 0 & & $\begin{array}{l}\text { Device is rated for } 95 \% \text { non condensing } \\
\text { at } 40 \mathrm{C} \text {. Low Humidity environment, no } \\
\text { effect. }\end{array}$ \\
\hline Calibration Uncertainty & 5.2 & & $4 \%$ of full scale (5.2A) \\
\hline Power Supply Effect & 0 & & $\begin{array}{l}\text { As long as within required values on } \\
\text { voltage supply, no effect. Voltage range } \\
\text { for the instrument is } 115 \mathrm{~V}+/-10 \% \text { and } 49 \\
\text { to } 100 \mathrm{~Hz} \text {. }\end{array}$ \\
\hline Element Accuracy & 5.20 & 0 & \\
\hline
\end{tabular}

The display accuracy of SY461-WT-II-350 is a combination of both SY272-WT-VFD-350 and SY461WT-II-350 and is given in the table below:

\begin{tabular}{|l|r|c|}
\hline Il-350 Loop Accuracy & & \\
\hline & Value & Units \\
\hline Loop Accuracy & 5.24 & Amps \\
\hline Loop Drift & 0 & Amps \\
\hline Total Loop Uncertainty & 5.24 & Amps \\
\hline
\end{tabular}

This gives a worst case inaccuracy of $5.24 \mathrm{~A}$ at $130 \mathrm{~A}$ draw. This value equates to just over $4 \%$ error at full scale.

\subsection{FLOW LOOPS}

\subsubsection{LOOP 367}

\section{LOOP DESCRIPTION}

This loop is composed of a sensing element, SY101-WT-FE-367, a flow indicating totalizer, SY101-WTFQIT-367, a total flow display, SY461-WT-FQI-367, and two flow indicators, SY101-WT-FI-367A and SY461-WT-FI-367B. SY101-WT-FE-367 is located in the prefabricated pump pit, SY101-WT-ENCL-350. SY101-WT-FQIT-367 is mounted just outside the transfer pump pit control panel, SY101-WT-CP-350A. 
SY101-WT-FI-367A is mounted on SY101-WT-CP-350A. SY461-WT-FQI-367 and SY461-WT-FI-367B are mounted on the DACS trailer control panel, SY461-WT-CP-350B.

SY101-WT-FE-367 converts the flow into a series of pulses proportional to the flow rate and sends the pulses to SY101-WT-FQIT-367. SY101-WT-FQIT-367 converts the pulsed signal into a digital display of the flow rate or a flow total. It also sends a pulsed signal to SY461-WT-FQI-367. SY101-WT-FQIT-367 also outputs a 4-20mA signal to both SY101-WT-FI-367A and SY 461-WT-FI-367B. SY461-WT-FQI-367 converts the pulsed signal received from SY101-WT-FQIT-367 into a digital display representing total flow. Both SY101-WT-FI-367A and SY461-WT-FI-367B convert the $4-20 \mathrm{~mA}$ signal received from SY101-WT-FQIT-367 into a digital display of the flow rate.

\section{SETPOINT BASIS}

SY101-WT-FQIT-367 and SY101-WT-FI-367A are to be used for process control and material balance and will be calibrated. SY461-WT-FQI-367 and SY461-WT-FI-367B are for information only and will not be calibrated. The required accuracy of the flow rate outputs of both SY101-WT-FQIT-367 and SY101-WTFI-367A is $\pm 1 \%$. The acceptable material balance error between the tank SY-102 level and SY101-WTFQIT-367 is $<5 \%$ total flow $/<2,000$. This error is checked during transfer by doing material balance calculations every other hour. Should the deviation in material balance exceed these limits, the process is stopped and evaluated. Before proceeding with the transfer, the total flow readout of SY101-WT-FQIT367 is reset to zero.

There are two types of information presented in this loop, the flow rate, and the total flow. The principle consideration for the flow rate in this section of the transfer process is to maintain flow at greater than $6 \mathrm{ft} / \mathrm{s}$ (Process Control Plan, HNF-4264, Rev. 0, Section 2.1.3) to prevent settling in the line. The anticipated flow rates are between $90 \mathrm{gpm}$ and $180 \mathrm{gpm}$, with a nominal value of $120 \mathrm{gpm}$ (Process Control Plan, HNF-4264, Rev. 0, Section 8.3.1). This is based on dilution ratios between 0.5 and 2:1 of water and waste and a waste flow rate of $60 \mathrm{gpm}$. Technically, there is no upper limit on the flow rate other than pump capabilities. The maximum pump rate of the dilution pump is $70 \mathrm{gpm}$ leading to a maximum flow rate of $210 \mathrm{gpm}$ based on a 2:1 dilution ratio (Process Control Plan, HNF-4264, Rev. 0, Section 5.7). As such, the flow rate base values for SY101-WT-FQIT-367, SY101-WT-FI-367A, and SY461-WT-FI-367B are 0210gpm.

The flow totalization function of is merely a displayed value. The critical element of a totalizer is that the maximum displayed value exceeds the expected total flow. The total flow transferred is anticipated to be 200kgal (Process Control Plan, HNF-4264, Rev. 0, Section 1). Enveloping values would require a display of a maximum of $450 \mathrm{kgal}$. This is based on a maximum anticipated waste transfer of $150 \mathrm{kgal}$ (Process Control Plan, HNF-4264, Rev. 0, Section 7.0) and a dilution ratio of 2:1. The total flow on SY101-WTFQIT-367 and SY461-WT-FQI-367 can be displayed to 9 digits.

\section{SETPOINT VALUES}

There are four points where data is displayed. The four points are SY101-WT-FQIT-367, SY461-WT-FQI367, SY101-WT-FI-367A and SY461-WT-FI-367B. SY101-WT-FQIT-367 presents two separate types of information, flow rate and total flow. SY101-WT-FI-367A provides flow rate information. Accuracy and calibration information for SY101-WT-FQIT-367 and SY101-WT-FI-367A are presented below. SY461WT-FQI-367 and SY461-WT-FI-367B are for information only, they will not be calibrated and no accuracy information is developed.

The accuracy of SY101-WT-FE-367 is incorporated in the accuracy of SY101-WT-FQIT-367. When SY101-WT-FQIT-367 acts in a total flow display mode the accuracy is calculated as follows: 


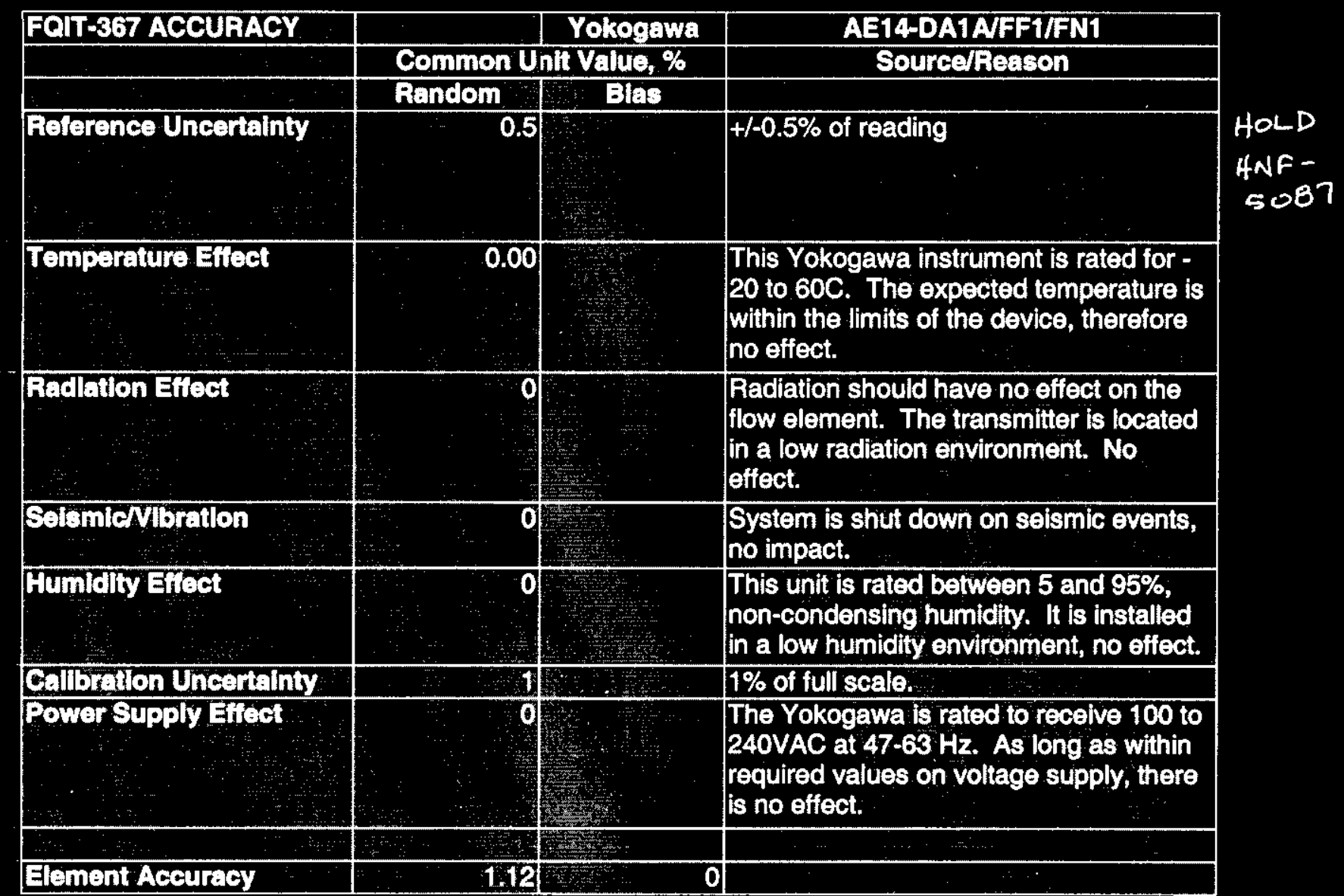

For information only, pending completion of tedinical review.

The accuracy of the display is given below:

\begin{tabular}{|l|c|c|}
\hline FolT-367 Loop Accuracy & & \\
\hline & Value & VTIS \\
\hline Loop Acouracy & 1.12 & $\%$ \\
\hline Loop Drif & 0 & $\%$ \\
\hline Total Loop Uncertainty & 1.12 & $\%$ \\
\hline
\end{tabular}

HOLD HNF -5087

For information only, pending completion of techinteal review.

This indicates that the total flow displayed on SY101-WT-FQIT-367 gives a total flow accuracy of $1.12 \%$ of total flow. It is understood that that value represents idealized conditions. These conditions, primarily at start up and shut down are far from ideal. These variations are not quantifiable but are to be expected. 
The accuracy of the flow rate displayed on SY101-WT-FQIT-367 is calculated below:

\begin{tabular}{|c|c|c|c|}
\hline FAT-867 ACCUAACY & & Yokogawa & AE14-DA1AFF1/FN1 \\
\hline & Common Unit & Value, GPM & Source/Reason \\
\hline & Fandom & Elas & \\
\hline Reference Uncertainty & 1.55 & & $\begin{array}{l}.5 \% \text { of the maximum range of the flow } \\
\text { meter, } 310 \mathrm{gpm} \text {. This includes the } \\
\text { uncertainty of the flow simulator used to } \\
\text { calibrate the FQIT. }\end{array}$ \\
\hline Temperature Effect & 0.00 & & $\begin{array}{l}\text { This Yokogawa instrument is rated for - } \\
20 \text { to } 60 \mathrm{C} \text {. The expected temperature is } \\
\text { within the limits of the device, therefore } \\
\text { no effect. }\end{array}$ \\
\hline Raclation Effect & & & $\begin{array}{l}\text { Radiation should have no effect on the } \\
\text { flow element. The transmitter is located } \\
\text { in a low radiation environment. No } \\
\text { effect. }\end{array}$ \\
\hline Salamientoration & 0 & & $\begin{array}{l}\text { System is shut down on selsmic events, } \\
\text { no impact. }\end{array}$ \\
\hline Humidity Efiect & & 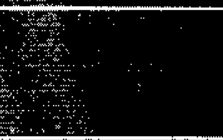 & $\begin{array}{l}\text { This unit is rated between } 5 \text { and } 95 \% \text {, } \\
\text { non condensing humidity. It is installed } \\
\text { in a low humidity environment, no effect. }\end{array}$ \\
\hline Calloralion Uncertainty & 3.1. & at: & $1 \%$ of full scale. \\
\hline Powor Supply Éfect & & 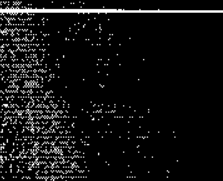 & $\begin{array}{l}\text { The Yokogawa is rated to receive } 100 \text { to } \\
240 \mathrm{VAC} \text { at } 47-63 \mathrm{~Hz} \text {. As long as within } \\
\text { required values on voltage supply, there } \\
\text { is no effect. }\end{array}$ \\
\hline 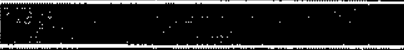 & - & sty & 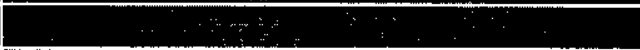 \\
\hline Element Accuracy & 3.472 & 2 & \\
\hline
\end{tabular}

For information only, pending completion of techitcal review.

The overall loop accuracy is then found:

\begin{tabular}{|c|c|c|}
\hline FaI-867 Loop Accuracy & & 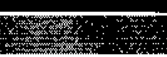 \\
\hline & Value & 1965 \\
\hline Loop Acotifacy. & 3.47 & GDM \\
\hline Loop Difl & 50 & QDDU \\
\hline Total Loop Uncertainty & 3.4 & GEM \\
\hline
\end{tabular}

HOLD

For information only, pending completion of techical review.

This indicates that flow rate readings on SY101-WT-FQIT-367 can be expected to read within $3.47 \mathrm{gpm}$. At a normal flow of $120 \mathrm{gpm}$, this display is within $\pm 2.89 \%$. 
Inaccuracies from SY 101-WT-FQIT-367 will cascade down to SY101-WT-FI-367A. The accuracy of the flow rate displayed on SY 101-WT-FI-367A, using the above values from SY101-WT-FQIT-367, is calculated below:

\begin{tabular}{|c|c|c|c|}
\hline F1-367A ACCURACY & & $\begin{array}{l}\text { Newport } \\
\text { Electronics }\end{array}$ & 558B-ET-IS1-SPC18 \\
\hline & \multicolumn{2}{|c|}{ Common Unit Value, GPM } & Source/Reason \\
\hline Beterence Uncertanty & Fandom & Blas & \\
\hline & & & $\begin{array}{l}\text {.1\% of flow rate, plus one digit. } \\
\text { Conservatively assumed maximum flow } \\
\text { of } 210 \mathrm{gpm} \text {. }\end{array}$ \\
\hline Temperature Eifect & 7.08 & & $\begin{array}{l}\text { The accuracy is based on a } 25 C \\
\text { temperature. Zero error is }+/ .3 \text { count/C. } \\
\text { Span error is } .015 \% \text { Span/C. These two } \\
\text { errors can be combined using the square } \\
\text { root of the sum of the squares method. } \\
\text { The } 350 \mathrm{~A} \text { panells assumed to have a } \\
\text { sell heating temperature rise of } 15 \mathrm{~F} \text {. } \\
\text { The Functional Requirements Document } \\
\text { gave an acceptable amblent transfer } \\
\text { temperature range of } 20-100 \mathrm{~F} \text {. The } \\
\text { greatest tempurature difference is } \\
23.33 \mathrm{C} \text {. Based on these extremes and } \\
\text { the equations, a maximum error is } 7.08 \\
\text { gpm and occurs at } 20 \mathrm{~F} \text { with a maximum } \\
\text { flow of } 210 \mathrm{gpm} \text { and a span of } 310 \mathrm{gpm} \text {. }\end{array}$ \\
\hline Radiation Efreet & & & $\begin{array}{l}\text { The panel meter is located in a low } \\
\text { radiation environment. }\end{array}$ \\
\hline Selsmionibration & & & $\begin{array}{l}\text { System is shut down on seismic events, } \\
\text { no impact. }\end{array}$ \\
\hline Humidity Bisect & & sis. & $\begin{array}{l}\text { The panel meter is rated for } 95 \% \\
\text { humidity, at } 40 \mathrm{C} \text {. It is located in a low } \\
\text { humidity environment, no effect }\end{array}$ \\
\hline Galbration Uncersainty & 3itis & (1) & $1 \%$ of full scale $(310 \mathrm{gpm})$ \\
\hline Power Supply Giect & 4. & $y$ & $\begin{array}{l}\text { As long as wilhin required values on } \\
\text { voltage supply, no effect. }\end{array}$ \\
\hline & & & \\
\hline Element Accuracy & 7.82 & 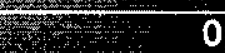 & \\
\hline
\end{tabular}

For information only, pending completion of technical review. 
The overall loop accuracy is then found:

\begin{tabular}{|l|r|c|}
\hline Fl-867 A Loop Accuracy & & \\
\hline & Value & Units \\
\hline Loop Acouracy & 8.56 & GPM \\
\hline Loop Drit & 0 & GPM \\
\hline Total Loop Uncertainty & 8.56 & GPM \\
\hline
\end{tabular}

HOLD

For information only, pending completion of technical review.

This gives a maximum error of any reading of SY101-WT-FI-367A as $8.56 \mathrm{gpm}$. At an average flow rate of $120 \mathrm{gpm}$, this represents a $7.13 \%$ error.

\subsubsection{LOOP 418}

\section{LOOP DESCRIPTION}

This loop is composed of a sensing element, POR32-RW-FE-418, a flow indicating totalizer, POR32-RWFQIT-418, a total flow display, POR32-RW-FQI-418, and a flow indicator, POR32-RW-FI-418. POR32RW-FE-418 and POR32-RW-FQIT-418 are located on the water skid. POR32-RW-FQI-418 and POR32RW-FI-418 are mounted in the water support skid electrical enclosure, POR32-RW-CP-401.

POR32-RW-FE-418 converts the flow into a series of pulses proportional to the flow rate and sends the pulses to POR32-RW-FQIT-418. POR32-RW-FQIT-418 converts the pulsed signal into a digital display of the flow rate or a flow total. It also sends a 4-20mA signal to both POR32-RW-FQI-418 and POR32-RWFI-418. POR32-RW-FQI-418 converts the 4-20mA signal received from POR32-RW-FQIT-41 8 into a digital display of the total flow. POR32-RW-FI-418 converts the 4-20mA signal received from POR32RW-FQIT-418 into a digital display of the flow rate.

\section{SETPOINT BASIS}

Information displayed by POR32-RW-FQIT-418, POR32-RW-FQI-418, and POR32-RW-FI-418 are for information only and these instruments will not be calibrated.

\subsubsection{LOOP 419}

\section{LOOP DESCRIPTION}

This loop is composed of a sensing element, POR32-RW-FE-419, a flow indicating totalizer, POR32-RWFQIT-419, a flow indicator, SY101-WT-FI-419, a flow indicator with contacts out SY461-RW-FIY-419, two relays, 2K2 and 2K3, and two windows on annunciator SY461-WT-ANN-350B, SY461-RW-FAL-419 and SY461-RW-FAH-419. POR32-RW-FE-419 and POR32-RW-FQIT-419 are located on the water supply valve and instrumentation stand assembly skid. POR32-RW-FI-419 is located in the SY-101 transfer pump pit control panel, SY101-WT-CP-350A. SY461-RW-FIY-419, relays 2K2 and 2K3, SY461RW-FAL-419 and SY461-RW-FAH-419 are mounted in the DACS trailer control panel, SY461-WT-CP350B.

POR32-RW-FE-419 converts the flow into a series of pulses proportional to the flow rate and sends the pulses to POR32-RW-FQIT-419. POR32-RW-FQIT-419 converts the pulsed signal into a digital display of the flow rate or a flow total. It also sends a 4-20mA signal to both SY 101-WT-FI-419 and SY461-RWFIY-419. SY101-WT-FI-419 converts the 4-20mA signal received from POR32-RW-FQIT-419 into a digital display of the flow rate. SY461-RW-FIY-419 converts the 4-20mA signal received from POR32RW-FQIT-419 into a digital display of the flow rate and also trips contacts for a low and high flow rate. 
The tripped contacts on SY461-RW-FIY-419 in turn trip relays $2 \mathrm{~K} 2$ and $2 \mathrm{~K} 3$ respectively actuating alarms SY461-RW-FAL-419 and SY461-RW-FAH-419 in SY461-WT-ANN-350B.

\section{SETPOINT BASIS}

There are two types of information presented in this loop, the flow rate, and the total flow. Additionally, there are alarm points for both high and low flow. The principle consideration for the flow rate in this section of the transfer process is to provide sufficient diluent to maintain the proper dilution ratios and the minimum flow of $6 \mathrm{ft} / \mathrm{s}$ in the transfer line to prevent settling (Process Control Plan, HNF-4264, Rev. 0, Section 2.1.3). The maximum flow rate of diluent is $70 \mathrm{gpm}$ due to pump and heater limitations. The anticipated flow rates are between $30 \mathrm{gpm}$ and $70 \mathrm{gpm}$, with a nominal value of $60 \mathrm{gpm}$ (Process Control Plan, HNF-4264, Rev. 0, Section 8.3.1). This is based on dilution ratios between 0.5 and 2:1 of water and waste and a projected waste flow rate of $60 \mathrm{gpm}$. As such, the flow rate base values for POR32-RW-FQIT419and SY101-WT-FI-419 are 0-70gpm.

The flow totalization function is merely a displayed value of the diluent. The critical element of a totalizer is that the maximum displayed value exceeds the expected total flow. The total waste transferred is anticipated to be 200kgal with an anticipated dilution ration of 1:1 (Process Control Plan, HNF-4264, Rev. 0 , Section 1). The maximum anticipated total flow of waste is $150 \mathrm{kgal}$. With a maximum dilution ratio of 2:1, the maximum diluent flow is 300kgal (Process Control Plan, HNF-4264, Rev. 0, Section 7.0). The total flow displayed on for POR32-RW-FQIT-419 exceeds the maximum expected total flow.

The alarm points are based on the minimum and maximum flows of diluent. These values are $20 \mathrm{gpm}$ and $70 \mathrm{gpm}$ respectively. The $20 \mathrm{gpm}$ is defined by the minimum flow rate of $60 \mathrm{gpm}$ to maintain the minimum $6 \mathrm{ft} / \mathrm{s}$ flow velocity (Process Control Plan, HNF-4264, Rev. 0, Section 2.1.3) and the minimum dilution ration of .5:1 diluent to waste (Process Control Plan, HNF-4264, Rev. 0, Section 7.2). The maximum flow rate of $70 \mathrm{gpm}$ is a function of the diluent pump and heaters.

\section{SETPOINT VALUES}

There are three points where data is displayed in this loop. Flow rate is displayed by POR32-RW-FQIT419, SY101-WT-FI-419, and SY461-RW-FIY-419. The total flow is only displayed on by POR32-RWFQIT-419. Alarms for both high and low flows are triggered via SY461-RW-FIY-419. 
The accuracy of POR32-RW-FE-419 is incorporated in the accuracy of POR32-RW -FQIT-419. When POR32-RW -FQIT-419 acts in a total flow display mode the accuracy is calculated as follows:

\begin{tabular}{|c|c|c|c|}
\hline FAT-419 ACCUAACY & & Brooks & 3525C3B1B111A \\
\hline & Common UnI & SValue, CPM & SourcelReason \\
\hline & Random & Blas & \\
\hline Reference Uncertainty & 0.5 & & $+/-0.5 \%$ of flow rate. \\
\hline Temperature Effect & 0.25 & & $\begin{array}{l}\text { Brooks flow transmitter gives a maximum } \\
\text { change of }+1-0.25 \% \text { change over the } \\
\text { operating temperature. }\end{array}$ \\
\hline Radiation Efrect & 0 & $\because$ & $\begin{array}{l}\text { The transmitter and element are located } \\
\text { in a low radiation environment, no effect. }\end{array}$ \\
\hline Solomlavibration & 0 & & $\begin{array}{l}\text { System is shut down on seismic events, } \\
\text { no impact. }\end{array}$ \\
\hline Humidly Elfoet & 0 & & $\begin{array}{l}\text { The transmitter is capable of handling } 0 \text { - } \\
100 \% \text { humidity at } 150 \mathrm{~F} \text {. No effect. }\end{array}$ \\
\hline Callbration Uncertainty & 1 & (1) & $1 \%$ of UAL \\
\hline Powar Supply Zfifect & 0 & s. & $\begin{array}{l}\text { Power requirements are 90-250VAC, 50- } \\
60 \mathrm{~Hz} \text {. No effect. }\end{array}$ \\
\hline & & 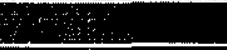 & \\
\hline Element Accuracy & 1.15 & 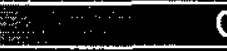 & \\
\hline
\end{tabular}

For information only, pending completion of techincal review.

The drift for this device is calculated below:

\begin{tabular}{|c|c|c|c|}
\hline FOIT-419 DAIFT & & Brooks & 3525C3B1B111A \\
\hline & Volue & Units & Source/Reason \\
\hline Wir value in \% UAL & 0.1 & $\%$ & Stability rate of $+1-0.1 \%$ per 6 mo. \\
\hline UAL & 273 & ePM & Eow element limitation \\
\hline Span & 273 & GDW & 整 \\
\hline Test intenal & 12 & mos & Eecall interval is $1 \mathrm{yr}$. \\
\hline Wir Interva & -6 & $\mathrm{mos}=$ & Brooks has a drift rate given in 6 mo. interval \\
\hline & & It & \\
\hline Element Dift & 0.20 & $\%$ & ${ }^{2}$ \\
\hline
\end{tabular}

$H \propto D$

HNF 5088

For information only, pending completion of technical review. 
The overall display accuracy for total flow is:

\begin{tabular}{|l|r|c|}
\hline FalT-419 Loop Accuracy & & \\
\hline & Value & Units \\
\hline Loop Accuracy & 1.15 & $\%$ \\
\hline Loop Drif & 0.2 & $\%$ \\
\hline Total Loop Uncertainty & 1.16 & $\%$ \\
\hline
\end{tabular}

HOLD

HNF 5088

For information only, pending completion of technical review.

This indicates that the total flow displayed on POR32-RW-FQIT-419 is accurate to within $1.16 \%$. It is understood that this value is given under idealized conditions. The conditions of this system, primarily at start up and shut down are far from ideal. These variations are not quantifiable but are to be expected.

Flow rate is also displayed by POR32-RW-FQIT-419. The accuracy of the display is calculated below:

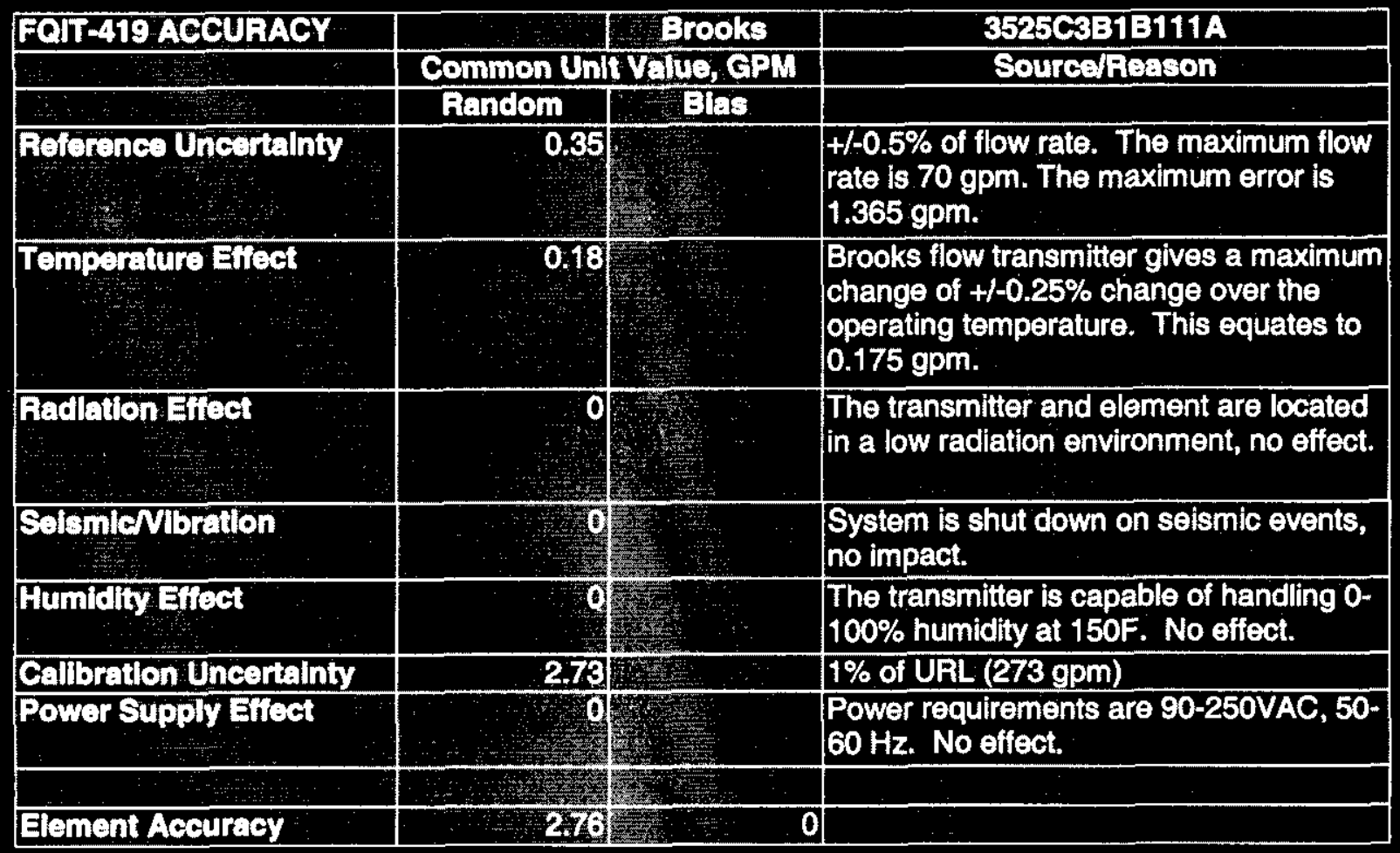

For information only, pending completion of techtical review.

HOLD

HNF 5088 
The drift of this instrument is given by:

\begin{tabular}{|l|r|c|l|}
\hline FalT-419 DAIFT & & Brooks & \multicolumn{1}{|c|}{ 3525C381B111A } \\
\hline & Value & Units & Sourcelieason \\
\hline Wir value in \% UAL & 0.1 & $\%$ & Stability rate of $+/-0.1 \%$ per 6 mo. \\
\hline UAL & 273 & GPM & Flow element limitation \\
\hline Span & 273 & GPM & \\
\hline Test Interval & 12 & mo & Recall interval is 1 yr. \\
\hline Wir Interval & 6 & mo & Brooks has a dritt rate given in 6 mo. interval \\
\hline & & & \\
\hline Element Drit & 0.55 & GPM & \\
\hline
\end{tabular}

$H \propto L D$

HNF-S088

For information only, pending completion of technical review.

The overall accuracy of the flow rate reading on POR32-RW-FQIT-419 is given below:

\begin{tabular}{|c|c|c|}
\hline FaIT-40 Loop Acouracy & & \\
\hline+3 & Value & Dins \\
\hline Loop Accuragy & 2.76 & cमn \\
\hline Loop Difi: & 0.546 & GPM \\
\hline Total Loop Uncartainty & 2.81 & बहn \\
\hline
\end{tabular}

HOLD

HNF-

5088

For information only, pending completion of technical review.

This indicates that flow rate readings on POR32-RW-FQIT-419 can be expected to read within $2.81 \mathrm{gpm}$. At a typical reading of $60 \mathrm{gpm}$, the displayed value is $\pm 4.68 \%$ of the actual flow rate. 


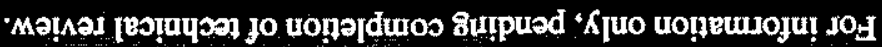

\begin{tabular}{|c|c|c|c|}
\hline & 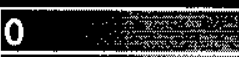 & 992 & Kopinooy yeurej \\
\hline & & & \\
\hline 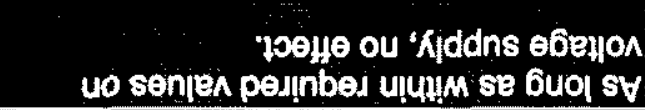 & & & were dudns tamod \\
\hline (udosLZ) ejeos |iny $10 \% 0^{\circ}$ & & 028 & 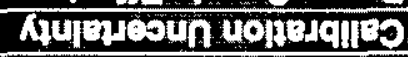 \\
\hline 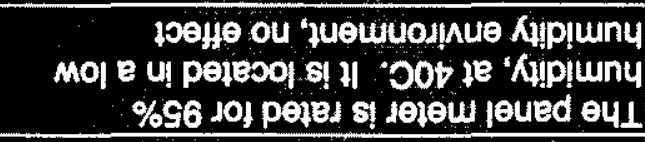 & & & Woug RYpunn \\
\hline $\begin{array}{l}\text { 'syuene opusjes uo umop inus s! uejs/s } \\
\end{array}$ & & 6 & uonetomp purges \\
\hline 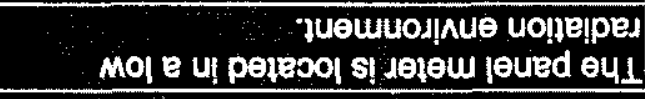 & & & weyg collojpar \\
\hline 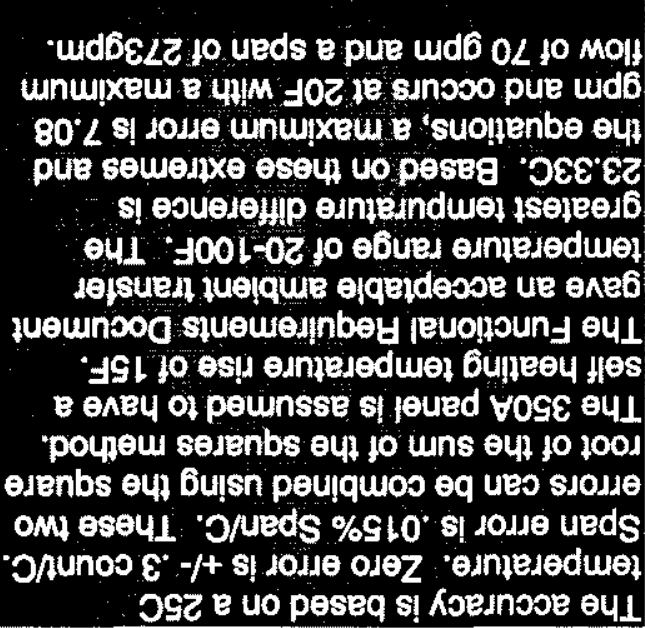 & & $90 \%$ & peug einivedued \\
\hline 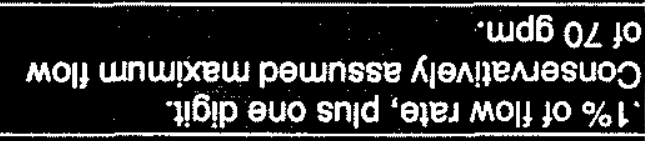 & & $\angle 0: 1$ & Ayupjesun esuarejey \\
\hline & 8919 & Hopusy & \\
\hline uosbeypasnos & Wde enjehs & fun voumos & \\
\hline 810dS-1SI-1E-g8g9 & $\begin{array}{l}\text { EDTuOjpe] } \\
\text { LodmeN }\end{array}$ & & 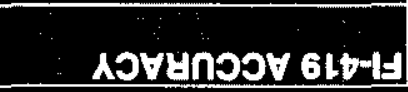 \\
\hline
\end{tabular}

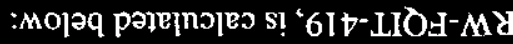

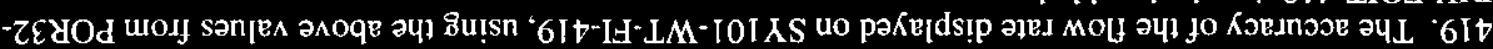

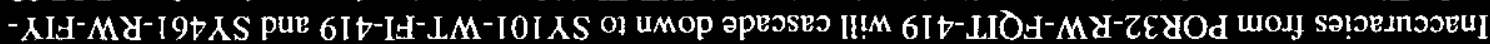


The accuracy of the readout from SY101-WT-FI-419 is found below:

\begin{tabular}{|l|r|r|}
\hline Fl-419 Loop Accuracy & & \\
\hline & Value & Units \\
\hline Loop Accuracy & 8.13 & GPM \\
\hline Loop Drif & 0.546 & GPM \\
\hline Total Loop Uncertainty & 8.15 & GPM \\
\hline
\end{tabular}

For information only, pending completion of technical review.

This indicates that flow rate on SY101-WT-FI-419 is within $8.15 \mathrm{gpm}$. At a reading of $60 \mathrm{gpm}$, this equates to an error of $\pm 13.58 \%$.

The accuracy of the flow rate displayed on SY461-RW-FIY-419, using the above values from POR32-RWFQIT-419, is calculated below:

\begin{tabular}{|c|c|c|c|}
\hline FIY-419 ACCURACY & & $\begin{array}{l}\text { Wowport } \\
\text { ADotwonics }\end{array}$ & INFP-0210-C2 \\
\hline & Common Un & IDणि कPM & Source/Reason \\
\hline 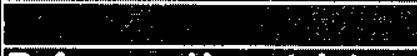 & Randoif & Blas & \\
\hline Reference Uncertalinty & & & $\begin{array}{l}.005 \% \text { of reading. Maximum value of } 70 \\
\text { gpm used. }\end{array}$ \\
\hline Temperature Bfect & & & $\begin{array}{l}\text { The accuracy is based on a } 25 \mathrm{C} \\
\text { temperature. Span error is } 20 \mathrm{ppm} / \mathrm{C} \text {. } \\
\text { The } 350 \mathrm{~B} \text { panel is assumed to have a } \\
\text { maximum temperature of } 92 \mathrm{~F} \text {, or } 8.33 \mathrm{C} \\
\text { above } 25 \mathrm{C} \text {. The error is expected to be } \\
\text { no greater than } 0.0002 \mathrm{gpm}\end{array}$ \\
\hline Radiatlon Elect & & & $\begin{array}{l}\text { DACs is a low radiation environment, no } \\
\text { effect anticipated. }\end{array}$ \\
\hline Selsmientbration & & & $\begin{array}{l}\text { System is shut down on seismic events, } \\
\text { no impact. }\end{array}$ \\
\hline Humidity Effect & & & $\begin{array}{l}\text { Device is rated for } 95 \% \text { non condensing } \\
\text { at } 40 \mathrm{C} \text {. Low Humidity environment, no } \\
\text { effect. }\end{array}$ \\
\hline Callbration Uneentalnty & 216 & & $1 \%$ of full scale \\
\hline Power Supply Eliset & & 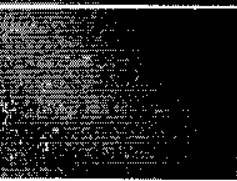 & $\begin{array}{l}\text { As long as within required values on } \\
\text { voltage supply, no effect. Voltage range } \\
\text { for the instrument is } 115 \mathrm{~V}+/-10 \% \text { and } 49 \\
\text { to } 100 \mathrm{~Hz} \text {. }\end{array}$ \\
\hline & & 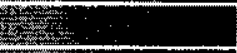 & \\
\hline Element Accuracy & 2.78 & 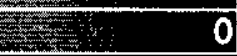 & \\
\hline
\end{tabular}

For information only, pending completion of technical review. 
The accuracy of the readout from SY461-RW-FIY-419 is found below:

\begin{tabular}{|l|r|c|}
\hline FIY-419 Loop Accuracy & & \\
\hline & Value & Units \\
\hline Loop Accuracy & 3.88 & GPM \\
\hline Loop Drlit & 0.546 & GPM \\
\hline Total Loop Uncertainty & 3.92 & GPM \\
\hline
\end{tabular}

$$
\begin{aligned}
& \text { HOLD } \\
& \text { HNF- } \\
& \text { SO8 } 8
\end{aligned}
$$

For information only, pending completion of technical review.

This indicates that flow rate on SY461-RW-FIY-419 is within $3.92 \mathrm{gpm}$. At an expected flow rate of 60

\begin{tabular}{|c|c|c|}
\hline FAL-419 Satpoint & & 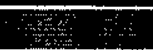 \\
\hline & Value & Units \\
\hline Alam Point & 20 & ePM \\
\hline Loop Uncartainty & 3.92 & CPM \\
\hline Margin & 1 & CPM \\
\hline Sotpolnt & 24.92 & GEM \\
\hline 5 & & 新 \\
\hline FAH-419 Sotpolnt & & -4 \\
\hline & Value & 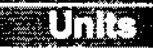 \\
\hline Alarm Point & 70 & CEN \\
\hline Loop Uncertainty & 3.92 & बPVI \\
\hline Wargin & 1 & EPM \\
\hline Sotpolnt & 65.08 & EPM \\
\hline
\end{tabular}
$\mathrm{gpm}$, this display is within $\pm 6.53 \%$.

The setpoints for SY461-RW-FAL-419 and SY461-RW-FAH-419 calculated below:

For information only, pending completion of technical review.

\subsection{LEAK DETECTION LOOPS}

\subsubsection{LOOP 365}

This loop is composed of an electrode sensing element, SY101-WT-LDE-365, leak detector circuitry mounted in a cabinet SY101-WT-LDSTA-365, with an alarm strobe mounted on top, SY101-WT-LDA365, a trip relay LDK-365 (1K1), a window on annunciator SY101-WT-ANN-350A, SY101-WT-LDA365A, and a window on annunciator SY461-WT-ANN-350B, SY461-WT-LDA-365B. SY 101-WT-LDE365 is located in the prefabricated pump pit, SY101-WT-ENCL-350. SY101-WT-LDSTA-365 is freestanding, located near the prefabricated pump pit, SY101-WT-ENCL-350 with SY101-WT-LDA-365 mounted on top. LDK-365 (1KI) and SY101-WT-LDA-365A are located in the SY-101 transfer pump pit control panel, SY101-WT-CP-350A. SY461-WT-LDA-365B is mounted in the DACS trailer control panel, SY461-WT-CP-350B.

\section{LOOP DESCRIPTION}

In the presence of waste, SY101-WT-LDE-365 will sense a resistance of less than $10 \mathrm{k} \Omega$ and trip the associated circuitry in SY101-WT-LDSTA-365. The internal circuitry initiates the alarm SY101-WTLDA-365 and trips relay LDK-365 (1K1). When relay LDK-365 (1K1) is tripped, it causes annunciation of both SY101-WT-LDA-365A and SY461-WT-LDA-365B. 


\section{SETPOINT BASIS}

The leak detector must detect a presence of waste material within the prefabricated pump pit at a level of 5/8" above the drain (Safety Equipment List for the 241-SY-101 RAPID Mitigation Project, HNF-4531, Rev. 1). It does this with an electrode and associated circuitry designed to trip in the presence of a less than $10 \mathrm{k} \Omega$ resistance (HNF-SD-WM-ER-736, Intrinsically safe leak detector circuit design description).

\section{SETPOINT VALUES}

There are two independent variables associated with accurate detection and annunciation of a leak. These are the position of the electrode and the functionality of the leak detection circuitry. The position of the electrode is set by design and limited to less than 2" in the BIO.

The leak detection circuitry is designed to trip upon the resistance between the electrode dropping below $10 \mathrm{k} \Omega$. The resistance of the waste can be expected to be significantly less than $100 \Omega$. As long as the circuit is properly hooked up, powered, and functioning, it will detect the presence of any leak that impacts the electrode. The circuit is failsafe and is tested on a periodic basis to assure continued function. This circuit is not calibratable.

\subsubsection{LOOP 366}

\section{LOOP DESCRIPTION}

This loop is composed of an electrode sensing element, SY101-WT-LDE-366, leak detector circuitry mounted in a cabinet SY101-WT-LDSTA-366, with an alarm strobe mounted on top, SY101-WT-LDA366, a trip relay LDK-366 (1K2), a window on annunciator SY101-WT-ANN-350A, SY101-WT-LDA366A, and a window on annunciator SY461-WT-ANN-350B, SY461-WT-LDA-366B. SY101-WT-LDE366 is located in SY 102 riser 007 extension. SY101-WT-LDSTA-366 is freestanding, located near the riser extension with SY101-WT-LDA-366 mounted on top. LDK-366 (1K2) and SY101-WT-LDA-366A are located in the SY-101 transfer pump pit control panel, SY101-WT-CP-350A. SY461-WT-LDA-366B is mounted in the DACS trailer control panel, SY461-WT-CP-350B.

In the presence of waste, SY101-WT-LDE-366 will sense a resistance of less than $10 \mathrm{k} \Omega$ and trip the associated circuitry in SY101-WT-LDSTA-366. The internal circuitry initiates the alarm SY101-WTLDA-366 and trips relay LDK-366 (1K2). When relay LDK-366 (1K2) is tripped, it causes annunciation of both SY101-WT-LDA-366A and SY461-WT-LDA-366B.

\section{SETPOINT BASIS}

The leak detector must detect a presence of waste material within the anti syphon slurry distributor riser extension at a depth of 1/2" above the drain (Safety Equipment List for the 241-SY-101 RAPID Mitigation Project, HNF-4531, Rev. 1). It does this with an electrode and associated circuitry designed to trip in the presence of a less than $10 \mathrm{k} \Omega$ resistance (HNF-SD-WM-ER-736, Intrinsically safe leak detector circuit design description).

\section{SETPOINT VALUES}

There are two independent variables associated with accurate detection and annunciation of a leak. These are the position of the electrode and the functionality of the leak detection circuitry. The position of the electrode is set by design and limited to less than $2 "$ in the BIO.

The leak detection circuitry is designed to trip upon the resistance between the electrode dropping below $10 \mathrm{k} \Omega$. The resistance of the waste can be expected to be significantly less than $100 \Omega$. As long as the circuit is properly hooked up, powered, and functioning, it will detect the presence of any leak that impacts 
the electrode. The circuit is failsafe and is tested on a periodic basis to assure continued function. This circuit is not calibratable.

\subsection{LEVEL LOOP}

\subsubsection{LOOP 416}

\section{LOOP DESCRIPTION}

This loop consists of a sensing element and switch POR32-RW-LE-416, four indicating lights, a high level, POR32-RW-LAH-416, a high high level POR32-RW-LAHH-416, a low level POR32-RW-LAL-416, and a low low level POR32-RW-LALL-416, four alarm strobe lights, a low low level POR32-RW-LALL-416A, a low, high, and high high, POR32-RW-LXA-416A, a second low low, POR32-RW-LALL-416B, a second low, high, and high high, POR32-RW-LXA-416B, and an alarm horn POR32-RW-YAH. POR32RW-LE-416, POR32-RW-LALL-416B, and POR32-RW-LXA-416B are located on the water support skid. POR32-RW-LAH-416, POR32-RW-LAHH-416, POR32-RW-LAL-416, POR32-RW-LALL-416, POR32RW-LALL-416A, POR32-RW-LXA-416A, and POR32-RW-YAH-416 are all located in or on the water support skid electrical enclosure POR32-RW-CP-401.

POR32-RW-LE-416 senses the level of raw water in the tank on the water skid. At various levels, switches in POR32-RW-LE-416 change state, causing the various indicator and alarm strobe lights, and the alarm horn to come on.

\section{SETPOINT BASIS}

The primary purpose of this loop is to provide indication that the level of the dilution water tank is getting too high or low. There are several concerns related to the level of the tank. These include:

1) The need to retain adequate volumetric capacity to flush the transfer pump and lines. This volume includes flushing the transfer line three times with a total volume of approximately 75 gallons and flushing the transfer pump and prefabricated pump pit piping at approximately 500-600 gallons. This total volume is estimated at 700 gallons.

2) The tank must have the capacity to provide this volume even if the upstream primary heated water source fails.

3) There must be sufficient surge capacity such that inlet water temperature transients are minimized by the large thermal mass of the water in the tank.

4) The maximum level in the tank must be kept below the overflow point.

5) The minimum water level must be sufficient to prevent damage to the heat panels and the fiberglass tank wall.

6) There needs to be sufficient volume in the operating range to prevent nuisance alarms.

The relationship between the level and the volume of the tank is derived as follows:

1) The tank has a seven foot inner diameter and is seven feet high at the intersection between the dome and the wall.

2) The bottom drain is located one inch above the bottom.

3) The top overflow is located five and a half inches below the seven foot level. 
This gives an effective available height of $771 / 2$ " (84"- 1 "'-5 1/2"). The available volume is approximately 1859 gallons $\left[\left\{(\pi / 4)^{*}\left(84^{\prime \prime}\right)^{2} * 77.5^{\prime \prime}\right\} /\left\{23 \mathrm{lin}^{3} /\right.\right.$ gal $\left.\}\right]$. Divided by the effective height of $77 \mathrm{1} / 2 "$, the height to volume ratio is approximately 1 in $=24$ gallons.

\section{SETPOINT VALUES}

1

There are four setpoints associated with this loop. The Magnetrol level switch has an accuracy of approximately $1 / 16$ " based on the instrument, the probe, the fluid being measured, and the tank configuration and material. Under the environmental conditions, there are no other significant inaccuracies. The setpoints are based on engineering judgement and the rational is given below. The level setpoints for the tank are primarily for information and as a consequence, the precision of the setpoint is not necessary. Therefore, the values developed will be used rather than developing alarm points that take error and margin into account. These values will take into account the points raised in the previous section. This loop will be functionally checked during operation and will not be calibrated on any scheduled basis.

\section{Low Low Level Setpoint}

The value for the low low level setpoint is developed as follows. A minimum of 700 gallons is needed to allow for flushing. 700 gallons is approximately 29". With the l" offset from the bottom for the drain, a setpoint of 30" is sufficient. It should be noted that the high temperature sensor, POR32-RW-TE-411B is located at 25 " up from the bottom of the tank.

Tripping this setpoint is considered an emergency condition. This is the only alarm point which alarms the red strobe lights, POR32-RW-LALL-416A and POR32-RW-LALL-416B. Also tripped are indicating light POR32-RW-LALL-416 and the alarm horn POR32-RW-YAH-416.

\section{Low Level Setpoint}

The low level alarm point is set 6" above the low low setpoint, or 36" above the bottom of the tank. The 6" gives approximately $2 \frac{1}{2}$ minutes for an operator to respond to a low level alarm before the low low alarm engages, assuming no flow into the tank and full flow out. This $21 / 2$ minutes is a buffer period for the operator to take action to maintain a normal tank level or to terminate the transfer if necessary. This alarm point trips the yellow strobe lights, POR32-RW-LXA-416A and POR32-RW-LXA-416B. Also tripped are indicating light POR32-RW-LAL-416 and the alarm horn POR32-RW-YAH-416. If POR32-RW-SOV401 is closed, it is opened. Closure could have automatically occurred if the level had reached the high high setpoint.

\section{High Level Setpoint}

The high level alarm point is set 28 " above the low level setpoint, or 64" above the bottom of the tank. This corresponds to an additional 672 gallons of water. Typically the operator will throttle the globe valve POR32-RW-V-401, to control flow into the tank such that the inflow and outflow are balanced. If the tank is at midpoint between high and low level (50"), it would take an error of $15 \%$ (10gpm) approximately 34 minutes to reach an alarm point. This should provide sufficient time for operators to make adjustments.

This alarm point trips the yellow strobe lights, POR32-RW-LXA-416A and POR32-RW-LXA-416B. Also tripped are indicating light POR32-RW-LAH-416 and the alarm horn POR32-RW-YAH-416.

\section{High High Level Setpoint}

The high high level alarm point is set 10" above the high level setpoint, or 74" above the bottom of the tank. At 74", the highest operational level in the tank, the water is approximately 4 inches below the overflow level. This additional volume above the high setpoint provides the operator with approximately

$\overline{1}$ Magnetrol is a trademark of Magnetrol Int'1., Inc. 
24 minutes of time to correct the flow rates, based on a $10 \mathrm{gpm}$ flow rate surplus. Once the alarm engages, POR32-RW-V-401 closes and the yellow strobe lights, POR32-RW-LXA-416A and POR32-RW-LXA$416 \mathrm{~B}$ are engaged. Also tripped are indicating light POR32-RW-LAHH-416 and the alarm horn POR32RW-YAH-416.

A longer buffer period of 10 inches between the high level and the high high level, as opposed to the 6 inches used between the low and low low levels, is needed due to other operational concerns. Closing POR32-RW-SOV-401stops the inflow of dilution water. When the flow drops below $15 \mathrm{gpm}$, the low flow interlock for flow from the heater to the water skid tank will turn off the heaters. The heaters must be manually reset following the reestablishment of flow. POR32-RW-SOV-401 is reopened when the tank has drained to the low level setpoint. It would take approximately 15 minutes to drop the level of the tank from the high high setpoint to the low setpoint assuming $60 \mathrm{gpm}$ outflow. This is sufficient time for the hot water heaters to cool down and allow temperatures of the diluent to drop below acceptable values.

The tank has adequate surge capacity to overcome temperature transients. As an example, if the tank is at the midpoint, $50^{\prime \prime}$, at $130^{\circ} \mathrm{F}$, it would take 4 minutes adding $32^{\circ} \mathrm{F}$ water, to drop the temperature of the tank twenty degrees.

\subsection{PRESSURE LOOPS}

\subsubsection{LOOP 368}

\section{LOOP DESCRIPTION}

This is a simple indication loop, consisting of a pressure element, SY 101-WT-PE-368 and a pressure indicator, SY101-WT-PI-368. SY101-WT-PE-368 is located in the prefabricated pump pit, SY101-WTENCL-350. SY101-WT-PI-368 is located in the SY-101 transfer pump pit control panel, SY101-WT-CP350A. The pressure element, SY101-WT-PE-368, sends out a millivolt signal proportional to the operating pressure in the piping manifold. The millivolt signal is received by the pressure indicator, SY101-WT-PI368 , which converts it into a digital display in psig.

\section{SETPOINT BASIS}

The primary function of this loop is to provide some indication of flow restriction in the transfer line. This would be identified by a rise in operating pressure, the greater the restriction, the higher the pressure. The expected operating pressure at this point is a function of head loss through the transfer line and preliminary calculations estimate the pressure to be approximately $40 \mathrm{psig}$. The instrument was initially selected to ensure that it could read over the maximum output pressure of the pump, on the order of $275 \mathrm{psig}$. Because the expected operating range is significantly lower and accuracy of the reading is not critical, the display range is to be set at $0-100$ psig.

\section{SETPOINT VALUES}

There is one point where data is displayed in this loop. Output pressure is displayed by SY101-WT-PI368. The accuracy of SY101-WT-PI-368 is effected by the cascading effects of error in SY101-WT-PE368. Each element accuracy is developed below, and then the loop accuracy, as displayed on SY101-WTPI-368, is developed. 
The pressure element, SY101-WT-PE-368, accuracy is given below:

\begin{tabular}{|c|c|c|c|}
\hline \multirow[t]{3}{*}{ PI-368 ACCURACY } & & Sensotec & \multirow{3}{*}{$\begin{array}{c}\text { AE213-56a } \\
\text { Source/Reason }\end{array}$} \\
\hline & \multicolumn{2}{|c|}{ Common Unit Value, PSIG } & \\
\hline & Random & Bias & \\
\hline Reference Uncertainty & 0.03 & & $\begin{array}{l}\text { Published data gives an accuracy of } \\
\text { pressure reading at }+/-0.03 \% \text { of full } \\
\text { scale. At a range of } 0-100 p s i g \text { maximum } \\
\text { error is } 0.03 \text { psig. }\end{array}$ \\
\hline Temperature Effect & 0.00 & & $\begin{array}{l}\text { Conversations with Sensotec indicate } \\
\text { that over the temperature range of } 30- \\
160 F \text {, there is no effect. Waste } \\
\text { temperature is within this range. }\end{array}$ \\
\hline Radiation Effect & 0 & & $\begin{array}{l}\text { The indicator is in a low radiation } \\
\text { environment. No effect. }\end{array}$ \\
\hline Seismic/Vibration & 0 & & $\begin{array}{l}\text { System is shut down on seismic events, } \\
\text { no impact. }\end{array}$ \\
\hline Humidity Effect & 0 & & Low humidity environment. No effect. \\
\hline Callbration Uncertainty & 5 & & $5 \%$ of URL (100psig) \\
\hline Power Supply Effect & 0 & & No data available, no anticipated effect. \\
\hline Element Accuracy & 5.00 & & \\
\hline
\end{tabular}

The pressure indicator, SY101-WT-PI-368 accuracy is now developed:

\begin{tabular}{|l|r|r|l|}
\hline PI-368 ACCURACY & & Sensotec & \multicolumn{1}{|c|}{ AE213-51C-56A-AA923 } \\
\hline & Common Unit Value, PSIG & \multicolumn{1}{|c|}{ Source/Reason } \\
\hline Reference Uncertainty & 0.03 & Blas & \\
\hline Temperature Effect & 0.00 & & $\begin{array}{l}\text { Published data gives an accuracy of } \\
\text { pressure reading at +/-0.03\% of full } \\
\text { scale. At a range of 0-100psig maximum } \\
\text { error is 0.03 psig. }\end{array}$ \\
\hline Radiation Effect & & $\begin{array}{l}\text { Conversations with Sensotec indicate } \\
\text { that over the temperature range of 30- } \\
160 F, \text { there is no effect. Waste } \\
\text { temperature is within this range. }\end{array}$ \\
\hline Seismic/Vibration & 0 & & $\begin{array}{l}\text { The indicator is in a low radiation } \\
\text { environment. No effect. }\end{array}$ \\
\hline Humidity Effect & 0 & $\begin{array}{l}\text { System is shut down on seismic events, } \\
\text { no impact. }\end{array}$ \\
\hline Calibration Uncertainty & & Low humidity environment. No effect. \\
\hline Power Supply Effect & & & $5 \%$ of URL (5psig) \\
\hline & & & No data available, no anticipated effect. \\
\hline Element Accuracy & 0 & & \\
\hline
\end{tabular}


The overall loop accuracy, as indicated on SY101-WT-PI-368 is calculated below:

\begin{tabular}{|l|r|r|}
\hline Pl-368 Loop Accuracy & & \\
\hline & Value & Unlts \\
\hline Loop Accuracy & 5.00 & PSIG \\
\hline Loop Drift & 0 & PSIG \\
\hline Total Loop Uncertainty & 5.00 & PSIG \\
\hline
\end{tabular}

This indicates that readings on SY101-WT-PI-368 can be anticipated to be within 5.0 psig of actual pressure. At an anticipated operating pressure of 40 psig, this is an error of $12.5 \%$.

\subsubsection{LOOP 370}

\section{LOOP DESCRIPTION}

This is primarily an alarm loop to indicate abnormal conditions. It consists of a pressure switch, SY101WT-PS-370, a relay, PSK-370 (1K3), a window on annunciator SY101-WT-ANN-350A, SY101-WTPAH-370A, and a window on annunciator SY461-WT-ANN-350B, SY461-WT-PAH-370B. SY101-WTPE-370 is located in the prefabricated pump pit, SY101-WT-ENCL-350. PSK-370 (1K3) and SY101-WTPAH-370A are located in the SY-101 transfer pump pit control panel, SY101-WT-CP-350A. SY461-WTPAH-370B is mounted in the DACS trailer control panel, SY461-WT-CP-350B.

The purpose of this loop is to detect possible waste migration toward the raw water system. If, during a transfer, waste moves back through the flush cross connect line toward prefabricated pump pit supply line, the pressure in that line will increase until it trips SY101-WT-PS-370, opening the NC contact and dropping out relay PSK-370 (1K3). When relay PSK-370 (1K3) is tripped, it causes annunciation of both SY101-WT-PAH-370A and SY461-WT-PAH-370B.

\section{SETPOINT BASIS}

The pressure switch is to switch at 15 psig (Safety Equipment List for the 241-SY-I01 RAPID Mitigation Project, HNF-4531, Rev. 1). The authorization basis is the BIO, which calls for values less that 20psig. An accuracy of 1.5 psig is sufficient, provided the setpoint, coupled with any error and calibration, maintains the values set in the authorization value. 


\section{SETPOINT VALUES}

The setpoint of SY101-WT-PS-370 is established by examining the accuracy of the pressure switch and giving an acceptable margin. The critical issue is that the $20 \mathrm{psig}$ value established in the BIO cannot be violated. As such, the project SEL gave a setpoint of $15 \mathrm{psig}$. To ensure that the switch actuates no higher than 15 psig, the actual setpoint is set at 15 psig minus the error and the margin. These values are developed as follows:

\begin{tabular}{|c|c|c|c|}
\hline PS-370 ACCURACY & & SOR & 6AP-JF2-U8-C1A-X \\
\hline & Common Unil & ue, PSIG & Source/Reason \\
\hline & Random & Bias & \\
\hline Reference Uncertainty & 0.3 & & $+/-0.3$ psig per SOR \\
\hline Temperature Effect & 0.00 & & $\begin{array}{l}\text { Ambient temperature limits on the device } \\
\text { is }-40 \text { to } 167 \mathrm{~F} \text {. Anticipated temperature } \\
\text { is } 130 \mathrm{~F} \text {. No effect. }\end{array}$ \\
\hline Radiation Effect & 0 & & $\begin{array}{l}\text { This is purely a mechanical device, no } \\
\text { anticipated effect due to radiation. }\end{array}$ \\
\hline Seismlc/Vibration & 0 & & $\begin{array}{l}\text { System is shut down on seismic events, } \\
\text { no impact. }\end{array}$ \\
\hline Humidity Effect & 0 & & No effect. \\
\hline Calibration Uncertainty & 0.75 & & $5 \%$ of set point \\
\hline Power Supply Effect & 0 & & $\begin{array}{l}\text { As long as within required values on } \\
\text { voltage supply, no effect. Voltage range } \\
\text { for the instrument is } 115 \mathrm{~V}+/-10 \% \text { and } 49 \\
\text { to } 100 \mathrm{~Hz} \text {. }\end{array}$ \\
\hline Element Accuracy & 0.81 & 0 & \\
\hline
\end{tabular}

As this element has no documented drift, the loop accuracy is purely a function of the switch accuracy:

\begin{tabular}{|l|r|c|}
\hline PS-370 Loop Accuracy & & \\
\hline & Value & Units \\
\hline Loop Accuracy & 0.81 & PSIG \\
\hline Loop Drift & 0 & PSIG \\
\hline Total Loop Uncertainty & 0.81 & PSIG \\
\hline
\end{tabular}

The setpoint is then 15 psig.

\subsubsection{LOOP 371}

\section{LOOP DESCRIPTION}

This is primarily an alarm loop to indicate abnormal conditions. It consists of a pressure switch, SY101WT-PS-371, a relay, PSK-371 (1K4), a window on annunciator SY101-WT-ANN-350A, SY101-WTPAH-371A, and a window on annunciator SY461-WT-ANN-350B, SY461-WT-PAH-371B. SY 101-WTPE-371 is located in the prefabricated pump pit, SY101-WT-ENCL-350. PSK-371 (1K4) and SY101-WTPAH-371A are located in the SY-101 transfer pump pit control panel, SY101-WT-CP-350A. SY461-WTPAH-371B is mounted in the DACS trailer control panel, SY461-WT-CP-350B.

The purpose of this loop is to detect possible waste migration toward the raw water system. If, during a transfer, waste moves back through the flush cross connect line toward prefabricated pump pit supply line, 
the pressure in that line will increase until it trips the trips SY 101-WT-PS-371, opening the NC contact and dropping out relay PSK-371 (1K4). When relay PSK-370 (1K4) is tripped, it causes annunciation of both SY101-WT-PAH-371A and SY461-WT-PAH-371B.

\section{SETPOINT BASIS}

The pressure switch is to switch at 15 psig (Safety Equipment List for the 241-SY-101 RAPID Mitigation Project, HNF-4531, Rev. 1). The authorization basis is the BIO, which calls for values less that 20psig. An accuracy of 1.5 psig is sufficient, provided the setpoint, coupled with any error and calibration, maintains the values set in the authorization value.

\section{SETPOINT VALUES}

The setpoint of SY101-WT-PS-371 is established by examining the accuracy of the pressure switch and giving an acceptable margin. The critical issue is that the 20 psig value established in the BIO cannot be violated. As such, the project SEL gave a setpoint of $15 \mathrm{psig}$. To ensure that the switch actuates no higher than 15 psig, the actual setpoint is set at 15 psig minus the error and the margin. These values are developed as follows:

\begin{tabular}{|c|c|c|c|}
\hline \multirow[t]{3}{*}{ PS-371 ACCURACY } & & SOR & 6AP-JF2-U8-C1A-X \\
\hline & \multicolumn{2}{|c|}{ Common Unit Value, PSIG } & Source/Reason \\
\hline & Random & Blas & \\
\hline Reference Uncertainty & 0.3 & & $+/-0.3$ psig per SOR \\
\hline Temperature Effect & 0.00 & & $\begin{array}{l}\text { Ambient temperature limits on the device } \\
\text { is }-40 \text { to } 167 \mathrm{~F} \text {. Anticipated temperature } \\
\text { is } 130 \mathrm{~F} \text {. No effect. }\end{array}$ \\
\hline Radiation Effect & 0 & & $\begin{array}{l}\text { This is purely a mechanical device, no } \\
\text { anticipated effect due to radiation. }\end{array}$ \\
\hline Seismic/Vibration & 0 & & $\begin{array}{l}\text { System is shut down on seismic events, } \\
\text { no impact. }\end{array}$ \\
\hline Humidity Effect & 0 & & No effect. \\
\hline Calibration Uncertainty & 0.75 & & $5 \%$ of set point \\
\hline Power Supply Effect & 0 & & $\begin{array}{l}\text { As long as within required values on } \\
\text { voltage supply, no effect. Voltage range } \\
\text { for the instrument is } 115 \mathrm{~V}+/-10 \% \text { and } 49 \\
\text { to } 100 \mathrm{~Hz} \text {. }\end{array}$ \\
\hline Element Accuracy & 0.81 & 0 & \\
\hline
\end{tabular}

As this element has no documented drift, the loop accuracy is purely a function of the switch accuracy:

\begin{tabular}{|l|r|r|}
\hline PS-371 Loop Accuracy & & \\
\hline & Value & Units \\
\hline Loop Accuracy & 0.81 & PSIG \\
\hline Loop Drift & 0 & PSIG \\
\hline Total Loop Uncertainty & 0.81 & PSIG \\
\hline
\end{tabular}

The setpoint is then 15 psig. 


\subsubsection{LOOP 417}

\section{LOOP DESCRIPTION}

This is a simple indication loop, consisting of a pressure indicating transmitter, POR32-RW-PIT-417 and a pressure indicator, POR32-RW-PI-417. POR32-RW-PIT-417 is located on the water skid. POR32-RW-PI417 is mounted in the water support skid electrical enclosure, POR32-RW-CP-401. The pressure indicating transmitter, POR32-RW-PIT-417, converts the pressure of the raw water into a digital display and a proportional $4-20 \mathrm{~mA}$ signal. The $4-20 \mathrm{~mA}$ signal is converted to a digital read out, in psig, by the pressure indicator, POR32-RW-PI-417.

\section{SETPOINT BASIS}

The design pressure of the water skid piping is set to $200 \mathrm{psig}$ (Procurement Specification, HNF 4043, Section 3.2.2).

\section{SETPOINT VALUES}

There are two points where information is displayed on this loop, POR32-RW-PIT-417 and POR32-RWPI-417. The inaccuracy of the transmitter, POR32-RW-PIT-417, will cascade down and degrade the accuracy of the reading on and POR32-RW-PI-417.

The accuracy of POR32-RW-PIT-417 is given below:

\begin{tabular}{|c|c|c|c|}
\hline PIT-417 ACCURACY & & Yokogawa & EJA-430A-EAS4B-92EAFF1/D1 \\
\hline & Common Unil & Value, PSIG & Source/Reason \\
\hline & Random & Bias & \\
\hline Reference Uncertainty & 0.1875 & & $\begin{array}{l}\text { Published data gives an accuracy of } \\
\text { pressure reading at }+/-0.075 \% \text { of the } \\
\text { span. The span is } 0-250 \text { psig which } \\
\text { gives an error of } .1875 \text { psig }\end{array}$ \\
\hline Temperature Bffect & 0.22 & & $\begin{array}{l}\text { The ambient temperature effect is } \\
+/-[0.084 \% \text { of Span }+0.017 \% \text { URL] for a } \\
\text { chage of } 50 F \text {. These values are } \\
\text { combined using the square root of the } \\
\text { sum of the squares. With a span of } 250 \\
\text { psig and a URL of } 430 \text { psig, and } \\
\text { conservatively taking worst value, the } \\
\text { maximum error is }+/-0.2224 \text { psig }\end{array}$ \\
\hline Radiation Effect & 0 & & $\begin{array}{l}\text { This element should be stable for the } \\
\text { limited duration of radiation exposure. }\end{array}$ \\
\hline Seismic/Vlbration & 0 & & $\begin{array}{l}\text { System is shut down on seismic events, } \\
\text { no impact. }\end{array}$ \\
\hline Humidity Effect & 0 & & $\begin{array}{l}\text { The device is rated for } 5-100 \% \mathrm{RH} \text { at } \\
40 \mathrm{C} \text {. No effect. }\end{array}$ \\
\hline Calibration Uncertainty & 12.5 & & $5 \%$ of full scale. \\
\hline Power Supply Effect & 0.043 & & $\begin{array}{l}+/ \cdot 0.005 \% \text { of URL per volt. } \\
\text { Conservatively assume } 2 \text { volts. }\end{array}$ \\
\hline Element Accuracy & 12.50 & $\mathbf{0}$ & \\
\hline
\end{tabular}


This device has published drift information and is incorporated below:

\begin{tabular}{|l|r|c|l|}
\hline PIT-417 DRIFT & & Yokogawa & \multicolumn{1}{|c|}{ EJA-430A-EAS4B-92EAFF1/D1 } \\
\hline & Value & Units & \multicolumn{1}{c|}{ Source/Reason } \\
\hline Mir value in \% UAL & 0.1 & $\%$ & Stability rate of $+/-0.1 \%$ of URL per 24 mo. \\
\hline URL & 430 & PSIG & $0-430 \mathrm{psig}$ \\
\hline Span & 250 & PSIG & $0-250 \mathrm{psig}$ \\
\hline Test Interval & 12 & mo. & Recall interval is 1 yr. \\
\hline Mifr Interval & 24 & mo. & Yokogawa has a drift rate given in 24 mo. interval \\
\hline & & & \\
\hline Element Drift & 0.37 & PSIG & \\
\hline
\end{tabular}

Combining these elements, an overall accuracy of the reading is established as follows:

\begin{tabular}{|l|r|l|}
\hline PIT-417 Loop Accuracy & & \\
\hline & \multicolumn{1}{|c|}{ Value } & Units \\
\hline Loop Accuracy & 12.50 & PSIG \\
\hline Loop Drift & 0.3698 & PSIG \\
\hline Total Loop Uncertainty & 12.51 & PSIG \\
\hline
\end{tabular}

This gives a maximum uncertainty of the reading on POR32-RW-PIT-417 as \pm 12.51 psig. At 200 psig, the pressure relief setting, this would be an error of $6.25 \%$. 
The accuracy of the pressure displayed on POR32-RW-PI-417 is now developed. The first step is to calculate the element accuracy of POR32-RW-PI-417, and then combine that value with the error from POR32-RW-PIT-417. This is done below:

\begin{tabular}{|c|c|c|c|}
\hline \multirow[t]{3}{*}{ PI-417 ACCURACY } & & Red Lion & \multirow{3}{*}{$\begin{array}{c}\text { CUB4LP00 } \\
\text { Source/Reason }\end{array}$} \\
\hline & \multicolumn{2}{|c|}{ Common Unit Value, PSIG } & \\
\hline & Random & Bias & \\
\hline Reference Uncertainty & 1.25 & & $\begin{array}{l}\text { Published data gives an accuracy of the } \\
\text { reading at }+/-(0.1 \%+1 \text { digit }) \text { at } 23 \mathrm{C} \text { and } \\
\text { less than } 85 \% \mathrm{RH} \text {. With a span of } 0-250 \\
\text { psig this equates to } 1.25\end{array}$ \\
\hline Temperature Effect & 2.96 & & $\begin{array}{l}\text { Temperature effect error is in two forms. } \\
\text { Zero offset at } 0.2 \text { digits/C and span error } \\
\text { at } 100 \text { ppm/C. These values are } \\
\text { combined using the square root of the } \\
\text { sum of the squares method. The } \\
\text { temperature in the water skid panel is } \\
\text { limited to } 100 \mathrm{~F} \text { or } 38 \mathrm{C} \text {. This gives a } \\
\text { temperature rise of } 15 \mathrm{C} \text { and an error of } \\
2.96 \text { psig. }\end{array}$ \\
\hline Radiation Effect & 0 & & $\begin{array}{l}\text { The indicator is in a low radiation } \\
\text { environment. No effect. }\end{array}$ \\
\hline Seismic/Vibration & 0 & & $\begin{array}{l}\text { System is shut down on seismic events, } \\
\text { no impact. }\end{array}$ \\
\hline Humidity Effect & 0 & & $\begin{array}{l}\text { Device is rated for } 85 \% \mathrm{RH} \text { max, non } \\
\text { condensing from } 0-60 \mathrm{C} \text {. It is mounted in } \\
\text { a low humidity environment. No effect. }\end{array}$ \\
\hline Calibration Uncertainty & 12.5 & & $5 \%$ of URL ( $250 \mathrm{psig})$ \\
\hline Power Supply Effect & 0 & & No data available, no anticipated effect. \\
\hline Element Accuracy & 12.91 & 0 & \\
\hline
\end{tabular}

The combined loop accuracy is given below:

\begin{tabular}{|l|r|r|}
\hline PI-417 Loop Accuracy & & \\
\hline & Value & Units \\
\hline Loop Accuracy & 17.97 & PSIG \\
\hline Loop Drift & 0.3698 & PSIG \\
\hline Total Loop Uncertainty & 17.97 & PSIG \\
\hline
\end{tabular}

This gives a maximum uncertainty of the reading on POR32-RW-PI-417 as $\pm 17.97 \mathrm{psig}$. At $200 \mathrm{psig}$, the pressure relief setting, this would be an error of $8.99 \%$. 


\subsubsection{LOOP 420}

\section{LOOP DESCRIPTION}

This is a simple indication loop, consisting of a pressure element, POR32-RW-PE-420 and a pressure indicator, SY 101-WT-PI-420. POR32-RW-PE-420 is located on the water supply valve and instrumentation stand assembly skid. SY 101-WT-PI-420 is located in the SY-101 transfer pump pit control panel, SY101-WT-CP-350A. The pressure element, POR32-RW-PE-420, sends out a millivolt signal proportional to the operating pressure in the water supply valve and instrumentation stand assembly skid piping. The millivolt signal is received by the pressure indicator, SY101-WT-PI-420, which converts it into a digital display in psig.

\section{SETPOINT BASIS}

The design pressure of the valve and instrument stand piping is set to 200 psig (Procurement Specification, HNF 4043, Section 3.2.2).

\section{SETPOINT VALUES}

There is one point where data is displayed in this loop. Output pressure is displayed by SY101-WT-PI420. The accuracy of SY101-WT-PI-420 is effected by the cascading effects of any error found in the output of POR32-RW-PE-420. Each element accuracy is developed below, and then the loop accuracy, as displayed on SY101-WT-PI-368, is developed.

The pressure element, POR32-RW-PE-420, accuracy is given below:

\begin{tabular}{|c|c|c|c|}
\hline \multirow[t]{3}{*}{ PE-420 ACCUAACY } & & Sensotec & FPG1CN,2U5B6A,1Y \\
\hline & \multicolumn{2}{|c|}{ Common Unit Value, PSIG } & Source/Reason \\
\hline & Random & Blas & \\
\hline Reference Uncertainty & 0.25 & & $\begin{array}{l}\text { Published data gives an accuracy of } \\
\text { pressure reading at }+/-0.1 \% \text { of full scale. } \\
\text { At a range of } 0-250 \text { psig maximum error } \\
\text { is } 0.25 \text { psig. }\end{array}$ \\
\hline Temperature Effect & 0.00 & & $\begin{array}{l}\text { Conversations with Sensotec indicate } \\
\text { that over the temperature range of } 30- \\
160 F, \text { there is no effect. Waste } \\
\text { temperature is within this range. }\end{array}$ \\
\hline Radiation Effect & 0 & & $\begin{array}{l}\text { This element should be stable for the } \\
\text { limited duration of radiation exposure. }\end{array}$ \\
\hline SeismicNibration & 0 & & $\begin{array}{l}\text { System is shut down on seismic events, } \\
\text { no impact. }\end{array}$ \\
\hline Humidity Effect & 0 & & No effect. \\
\hline Callbration Uncertainty & 0 & & Calibrated as an integral unit with $\mathrm{PI}-368$ \\
\hline Power Supply Effect & 0 & & Indicator powered, no effect. \\
\hline Element Accuracy & 0.25 & 0 & \\
\hline
\end{tabular}


The pressure indicator, SY 101-WT-PI-420, accuracy is now developed:

\begin{tabular}{|c|c|c|c|}
\hline \multirow[t]{3}{*}{ Pl-420 ACCURACY } & & Sensotec & \multirow{2}{*}{$\begin{array}{c}\text { AE213-51C-56A-AA923 } \\
\text { Source/Reason }\end{array}$} \\
\hline & \multicolumn{2}{|c|}{ Common Unit Value, PSIG } & \\
\hline & Random & Blas & \\
\hline Reference Uncertainty & 0.075 & & $\begin{array}{l}\text { Published data gives an accuracy of } \\
\text { pressure reading at }+/-0.03 \% \text { of full } \\
\text { scale. At a range of } 0-250 \text { psig maximum } \\
\text { error is } 0.25 \text { psig. }\end{array}$ \\
\hline Temperature Effect & 0.00 & & $\begin{array}{l}\text { Conversations with Sensotec indicate } \\
\text { that over the temperature range of } 30- \\
160 F \text {, there is no effect. Waste } \\
\text { temperature is within this range. }\end{array}$ \\
\hline Radiation Effect & 0 & & $\begin{array}{l}\text { The indicator is in a low radiation } \\
\text { environment. No effect. }\end{array}$ \\
\hline Seismic/Vibration & 0 & & $\begin{array}{l}\text { System is shut down on seismic events, } \\
\text { no impact. }\end{array}$ \\
\hline Humidity Effect & 0 & & Low humidity environment. No effect. \\
\hline Callbration Uncertainty & 12.5 & & $5 \%$ of URL (250psig) \\
\hline Power Supply Effect & 0 & & No data available, no anticipated effect. \\
\hline Element Accuracy & 12.50 & 0 & \\
\hline
\end{tabular}

The overall loop accuracy, as indicated on SY101-WT-PI-420 is calculated below:

\begin{tabular}{|l|r|r|}
\hline Pl-420 Loop Accuracy & & \\
\hline & Value & Units \\
\hline Loop Accuracy & 12.50 & PSIG \\
\hline Loop Drift & 0 & PSIG \\
\hline Total Loop Uncertainty & 12.50 & PSIG \\
\hline
\end{tabular}

This indicates that readings on SY101-WT-PI-420 can be anticipated to be within $12.5 \mathrm{psig}$ of actual pressure. At a maximum operating pressure of $200 \mathrm{psig}$, this is an error of $6.25 \%$.

\subsection{TEMPERATURE LOOPS}

\subsubsection{LOOP 369}

\section{LOOP DESCRIPTION}

This loop is a simple indicating loop and is composed of a temperature sensing element, SY 101-WT-TE369, a temperature transmitter, SY101-WT-TT-369, and two temperature indicators, SY101-WT-TI-369A and SY461-WT-TI-369B. SY101-WT-TE-369 is located in the prefabricated pump pit, SY101-WT-ENCL350. SY101-WT-TT-369 and SY101-WT-TI-369A are mounted in the transfer pump pit control panel, SY101-WT-CP-350A. SY461-WT-TI-369B is mounted on the DACS trailer control panel, SY461-WTCP-350B.

SY101-WT-TE-369 is an RTD, which changes resistance in a circuit proportional to a temperature change. Circuitry within SY101-WT-TT-369 converts that input into a 4-20mA signal proportional to the temperature sensed. The $4-20 \mathrm{~mA}$ signal is then converted to a digital temperature read out by both SY101WT-TI-369A and SY461-WT-TI-369B. 


\section{SETPOINT BASIS}

The transfer temperature is between $110^{\circ} \mathrm{F}$ and $130^{\circ} \mathrm{F}$ (Process Control Plan, HNF-4264, Rev. 0, Section 5.7) with a target temperature of $120^{\circ} \mathrm{F}$ (Process Control Plan, HNF-4264, Rev. 0, Section 2.1.2).

\section{SETPOINT VALUES}

The waste temperature being transferred must be displayed on SY 101-WT-TI-369A and SY461-WT-TI369B. To that end, the range of these indicators must envelop the anticipated waste temperature.

Temperature indicators TI-369A and TI-369B have been set to a range of $32^{\circ} \mathrm{F}$ to $212^{\circ} \mathrm{F}$, which envelops the anticipated operating conditions.

The accuracy of the reading of SY101-WT-TI-369A is quantified by combining the inaccuracies and drift from each element in the instrument loop. The elements are SY101-WT-TE-369, SY101-WT-TT-369, and SY101-WT-TI-369A. Each element accuracy is given below. Drift values only exist for SY101-WT-TE369 , other elements are assumed to have negligible drift as they are solid state devices.

The accuracy of SY 101-WT-TE-369 is as follows:

\begin{tabular}{|c|c|c|c|}
\hline \multirow[t]{3}{*}{ TE-369 ACCURACY } & & Pyromation & RBF185RC3-3-9300-3 \\
\hline & \multicolumn{2}{|c|}{$\begin{array}{l}\text { Common Unit Value, } \\
\text { Degrees F }\end{array}$} & Source/Reason \\
\hline & Random & Bias & \\
\hline Reference Uncertainty & 0.12 & & $\begin{array}{l}\text { Published data gives an accuracy of }+/- \\
0.12 \% \text { at } 0 \mathrm{C} \text {. In other words, the } \\
\text { resistance is } 100 \text { ohms }+/-0.12 \mathrm{~F} \text {. This } \\
\text { offset is constant for the operating range } \\
\text { of this process. }\end{array}$ \\
\hline Temperature Effect & 0.00 & & No effect. \\
\hline Radiation Effect & 0 & & $\begin{array}{l}\text { This element should be stable for the } \\
\text { limited duration of radiation exposure. }\end{array}$ \\
\hline Seismic/Vibration & 0 & & $\begin{array}{l}\text { System is shut down on seismic events, } \\
\text { no impact. }\end{array}$ \\
\hline Humidity Effect & 0 & & No effect. \\
\hline Calibration Uncertainty & 0 & & Non calibratable device. \\
\hline Power Supply Effect & 0 & & Transmitter powered, no effect. \\
\hline Element Accuracy & 0.12 & 0 & \\
\hline
\end{tabular}


The drift for SY101-WT-TE-369 is found below:

\begin{tabular}{|c|c|c|c|}
\hline TE-369 DRIFT & & $\begin{array}{c}\text { Pyromatio } \\
n\end{array}$ & RBF185RG3-3-9300-3 \\
\hline & Value & Units & Source/Reason \\
\hline Mfr value In \% URL & 0.009 & Degrees F & ISA Text on Temperature Measurement gives $0.05 \mathrm{C} / \mathrm{yr}$ \\
\hline$\overline{\text { URL }}$ & 900 & Degrees F & $\begin{array}{l}\text { ISA Text on Temperature Measurement gives URL of } \\
900 \mathrm{~F}\end{array}$ \\
\hline Span & 180 & Degrees F & 180 degrees $F$ \\
\hline Test Interval & 12 & mo. & Recall interval is $1 \mathrm{yr}$. \\
\hline Mir Interval & 12 & mo. & \\
\hline Element Drift & 0.41 & Degrees F & \\
\hline
\end{tabular}

The inaccuracy of SY 101-WT-TT-369 is established as follows:

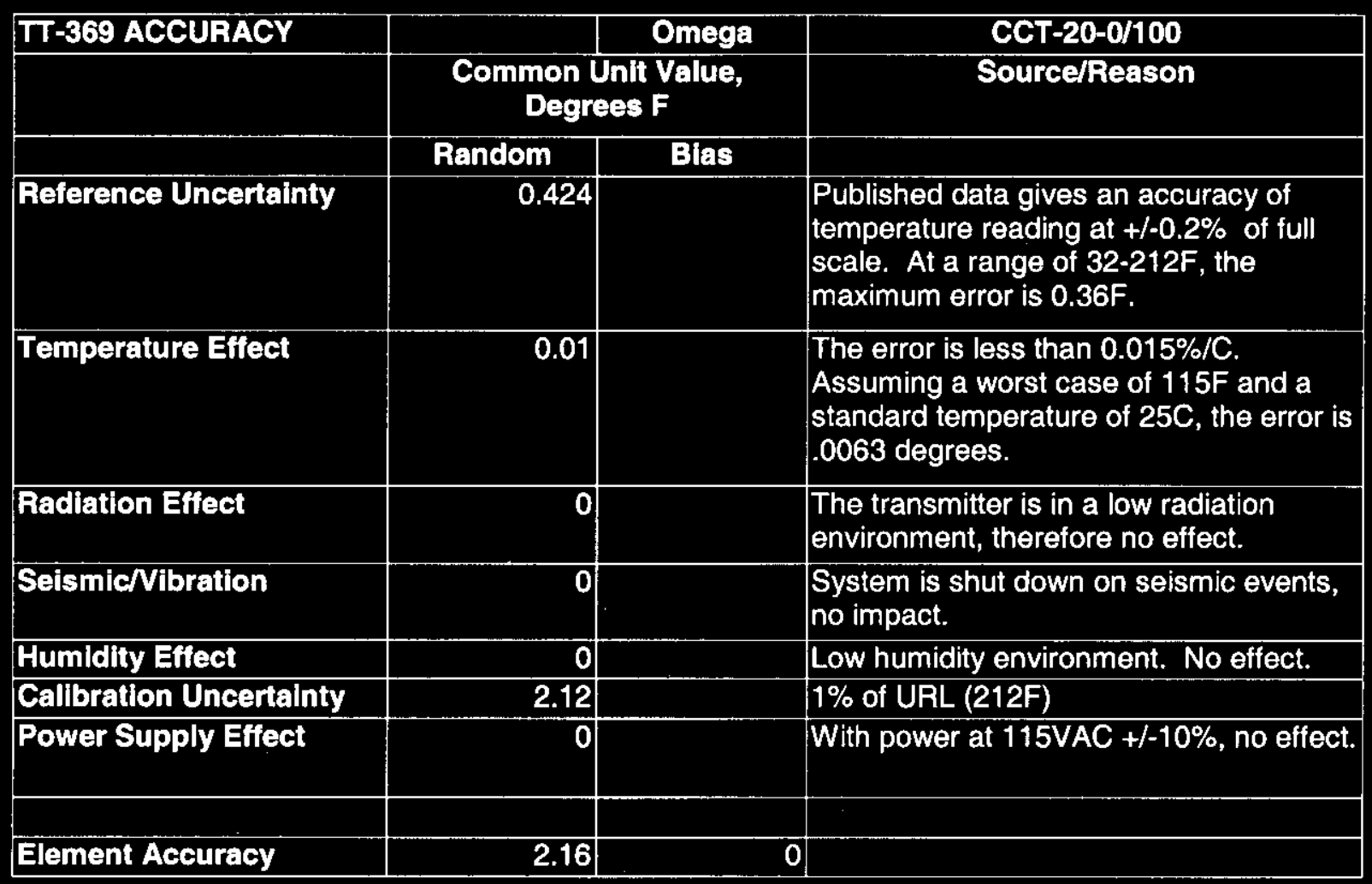


The inaccuracy of SY 101-WT-TI-369A is given below:

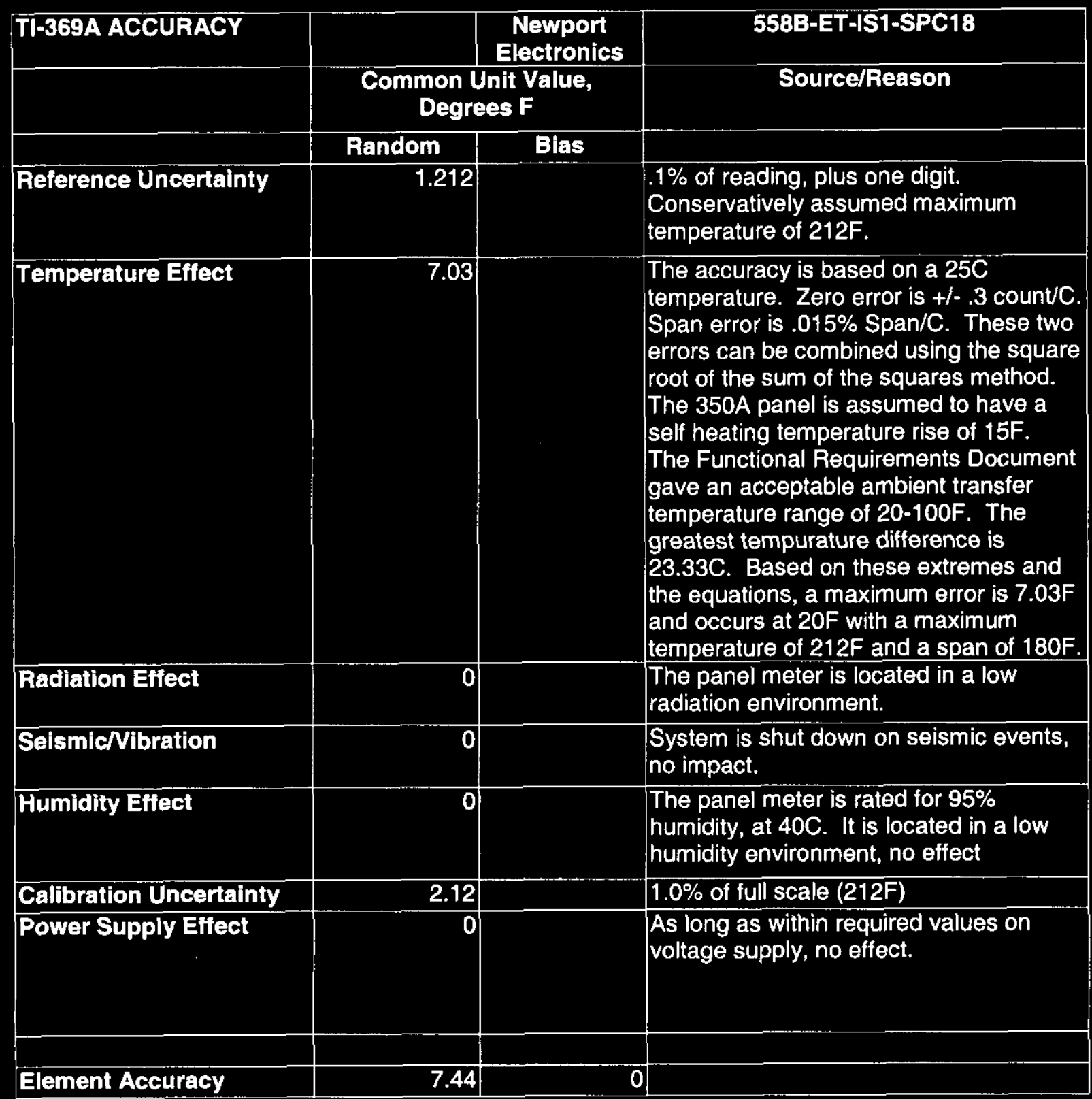

All of these element inaccuracies are combined to find a loop inaccuracy:

\begin{tabular}{|l|r|l|}
\hline Tl-369A Loop Accuracy & & \\
\hline & Value & Units \\
\hline Loop Accuracy & 7.75 & Degrees F \\
\hline Loop Drift & 0.405 & Degrees F \\
\hline Total Loop Uncertainty & 7.76 & Degrees F \\
\hline
\end{tabular}

This indicates that a typical reading of $130^{\circ} \mathrm{F}$ could be in error by $\pm 7.75^{\circ} \mathrm{F}$, or $\pm 5.96 \%$ 
The accuracy of the reading of SY101-WT-TI-369B is quantified by combining the inaccuracies and drift from each element in the instrument loop. These elements are SY 101-WT-TE-369, SY 101-WT-TT-369, and SY101-WT-TI-369A. Accuracies of SY101-WT-TE-369, SY101-WT-TT-369 were given above. The accuracy of SY101-WT-TI-369B and the combined loop accuracy is established below.

\begin{tabular}{|c|c|c|c|}
\hline \multirow[t]{2}{*}{ TI-369B ACCURACY } & & $\begin{array}{l}\text { Newport } \\
\text { Electronics }\end{array}$ & INFP-0210-C2 \\
\hline & \multicolumn{2}{|c|}{$\begin{array}{l}\text { Common Unit Value, } \\
\text { Degrees F }\end{array}$} & Source/Reason \\
\hline & Random & Blas & \\
\hline Reference Uncertainty & 0.0106 & & $\begin{array}{l}.005 \% \text { of reading. Maximum value of } \\
212 \mathrm{~F} \text { used. }\end{array}$ \\
\hline Temperature Effect & 0.00 & & $\begin{array}{l}\text { The accuracy is based on a } 25 \mathrm{C} \\
\text { temperature. Span error is } 20 \mathrm{ppm} / \mathrm{C} \text {. } \\
\text { The } 350 \mathrm{~B} \text { panel is assumed to have a } \\
\text { maximum temperature of } 92 \mathrm{~F} \text {, or } 8.33 \mathrm{C} \\
\text { above } 25 \mathrm{C} \text {. The error is expected to be } \\
\text { no greater than } 0.0002 \mathrm{~F}\end{array}$ \\
\hline Radiation Effect & 0 & & $\begin{array}{l}\text { DACs is a low radiation environment, no } \\
\text { effect anticipated. }\end{array}$ \\
\hline Seismic/Vibration & 0 & & $\begin{array}{l}\text { System is shut down on seismic events, } \\
\text { no impact. }\end{array}$ \\
\hline Humidity Effect & 0 & & $\begin{array}{l}\text { Device is rated for } 95 \% \text { non condensing } \\
\text { at } 40 \mathrm{C} \text {. Low Humidity environment, no } \\
\text { effect. }\end{array}$ \\
\hline Callbration Uncertainty & 2.12 & & $1 \%$ of full scale \\
\hline Power Supply Effect & 0 & & $\begin{array}{l}\text { As long as within required values on } \\
\text { voltage supply, no effect. Voltage range } \\
\text { for the instrument is } 115 \mathrm{~V}+/-10 \% \text { and } 49 \\
\text { to } 100 \mathrm{~Hz} \text {. }\end{array}$ \\
\hline Element Accuracy & 2.12 & 0 & \\
\hline
\end{tabular}

All of these element inaccuracies are combined to find a loop inaccuracy:

\begin{tabular}{|l|r|c|}
\hline Ti-369B Loop Accuracy & & \\
\hline & \multicolumn{1}{|c|}{ Value } & Units \\
\hline Loop Accuracy & $\mathbf{3 . 0 2}$ & Degrees F \\
\hline Loop Drift & 0.405 & Degrees F \\
\hline Total Loop Uncertainty & $\mathbf{3 . 0 5}$ & Degrees F \\
\hline
\end{tabular}

This indicates that a typical reading of $130^{\circ} \mathrm{F}$ could be in error by $\pm 3.05^{\circ} \mathrm{F}$, or $\pm 2.35 \%$ 


\subsubsection{LOOP 373}

\section{LOOP DESCRIPTION}

This loop is composed of a temperature sensing element, SY101-WT-TE-373, a temperature transmitter, SY101-WT-TT-373, a temperature indicator, SY101-WT-TI-373, a temperature indicator with contacts out, SY461-RW-TIY-373, a low dilution water temperature relay, 2K4, a window on annunciator SY101WT-ANN-350A, SY101-WT-TAL-373A, and a window on annunciator SY461-WT-ANN-350B, SY461WT-TAL-373B. SY101-WT-TE-373 is located in the prefabricated pump pit, SY101-WT-ENCL-350. 2K4, SY461-RW-TIY-373 and SY461-WT-TAL-373B are located in the DACS trailer control panel, SY461-WT-CP-350B. SY 101-WT-TI-373 and SY101-WT-TAL-373A are found in the SY-101 transfer pump pit control panel, SY101-WT-CP-350A. SY101-WT-TT-373 is mounted just outside the same panel.

The purpose of this loop is to provide temperature indication and to ensure that the diluent water temperature is maintained in the correct temperature range. If the diluent water temperature drops below a minimum value of $110^{\circ} \mathrm{F}$, alarms are to be sounded in the annunciator panels. SY 101-WT-TE-373 is an RTD, which changes resistance in a circuit proportional to a temperature change. Circuitry in SY101-WTTT -373 converts that input into a $4-20 \mathrm{~mA}$ signal proportional to the temperature sensed. The $4-20 \mathrm{~mA}$ signal is then converted to a digital temperature read out by both SY101-WT-TI-373 and SY461-RW-TIY373. SY461-RW-TIY-373 also has trip contacts for a low temperature. The tripped contact in SY461-RWTIY-373 in turn trips relay 2K4, actuating alarms SY101-WT-TAL-373A and SY461-WT-TAL-373B.

\section{SETPOINT BASIS}

The dilution water temperature is to be between $110^{\circ} \mathrm{F}$ and $130^{\circ} \mathrm{F}$ (Process Control Plan, HNF-4264, Rev. 0 , Section 2.1.1).

\section{SETPOINT VALUES}

The dilution water temperature is to be displayed on SY101-WT-TI-373 and SY461-RW-TIY-373. To that end, the range of these indicators must envelop the anticipated water temperature. Temperature indicator SY 101-WT-TI- 373 has been set to a range of $32^{\circ} \mathrm{F}$ to $212^{\circ} \mathrm{F}$, which envelops the anticipated operating conditions. The alarms, SY101-WT-TAL-373A and SY461-WT-TAL-373B are nominally set for $110^{\circ} \mathrm{F}$ as this is the low end of the desired temperature range.

The accuracy of the reading of SY101-WT-TI-373 is quantified by combining the inaccuracies and drift from each element in the instrument loop. The elements are SY101-WT-TE-373, SY101-WT-TT-373, and SY461-WT-TIY-373. Each element accuracy is given below. Drift values only exist for SY101-WT-TE373 , other elements are assumed to have negligible drift as they are solid state devices. 
The accuracy of SY101-WT-TE-373 is as follows:

\begin{tabular}{|c|c|c|c|}
\hline TE-373 ACCURACY & & Pyromation & RBF185RG3-3-9300-3 \\
\hline & $\begin{array}{l}\text { Common l } \\
\text { Degr }\end{array}$ & $\begin{array}{l}\text { Unit Value, } \\
\text { ees F }\end{array}$ & Source/Reason \\
\hline & Random & Bias & \\
\hline Reference Uncertainty & 0.12 & & $\begin{array}{l}\text { Published data gives an accuracy of }+/- \\
0.12 \% \text { at } 0 \mathrm{C} \text {. In other words, the } \\
\text { resistance is } 100 \text { ohms }+/-0.12 \mathrm{~F} \text {. This } \\
\text { offset is constant for the operating range } \\
\text { of this process. }\end{array}$ \\
\hline Temperature Effect & 0.00 & & No effect. \\
\hline Radiation Effect & 0 & & $\begin{array}{l}\text { This element should be stable for the } \\
\text { limited duration of radiation exposure. }\end{array}$ \\
\hline Seismic/Vibration & 0 & & $\begin{array}{l}\text { System is shut down on seismic events, } \\
\text { no impact. }\end{array}$ \\
\hline Humidity Effect & 0 & & No effect. \\
\hline Calibration Uncertainty & 0 & & Non calibratable device. \\
\hline Power Supply Effect & 0 & & Transmitter powered, no effect. \\
\hline Element Accuracy & 0.12 & & \\
\hline
\end{tabular}

The drift for SY 101-WT-TE-373 is found below:

\begin{tabular}{|l|r|r|l|}
\hline TE-373 DRIFT & & $\begin{array}{c}\text { Pyromatio } \\
n\end{array}$ & RBF185RG3-3-9300-3 \\
\hline & Value & Units & \multicolumn{1}{|c|}{ Source/Reason } \\
\hline Mir value in \% URL & 0.009 & Degrees F & ISA Text on Temperature Measurement gives 0.05C/yr \\
\hline URL & 900 & Degrees F & $\begin{array}{l}\text { ISA Text on Temperature Measurement gives URL of } \\
900 \mathrm{~F}\end{array}$ \\
\hline Span & 180 & Degrees F & 180 degrees F \\
\hline Test Interval & 12 & mo. & Recall interval is 1 yr. \\
\hline Mfr Interval & 12 & mo. & \\
\hline & & & \\
\hline Element Drift & 0.41 & Degrees F & \\
\hline
\end{tabular}


The inaccuracy of SY101-WT-TT-373 is established as follows:

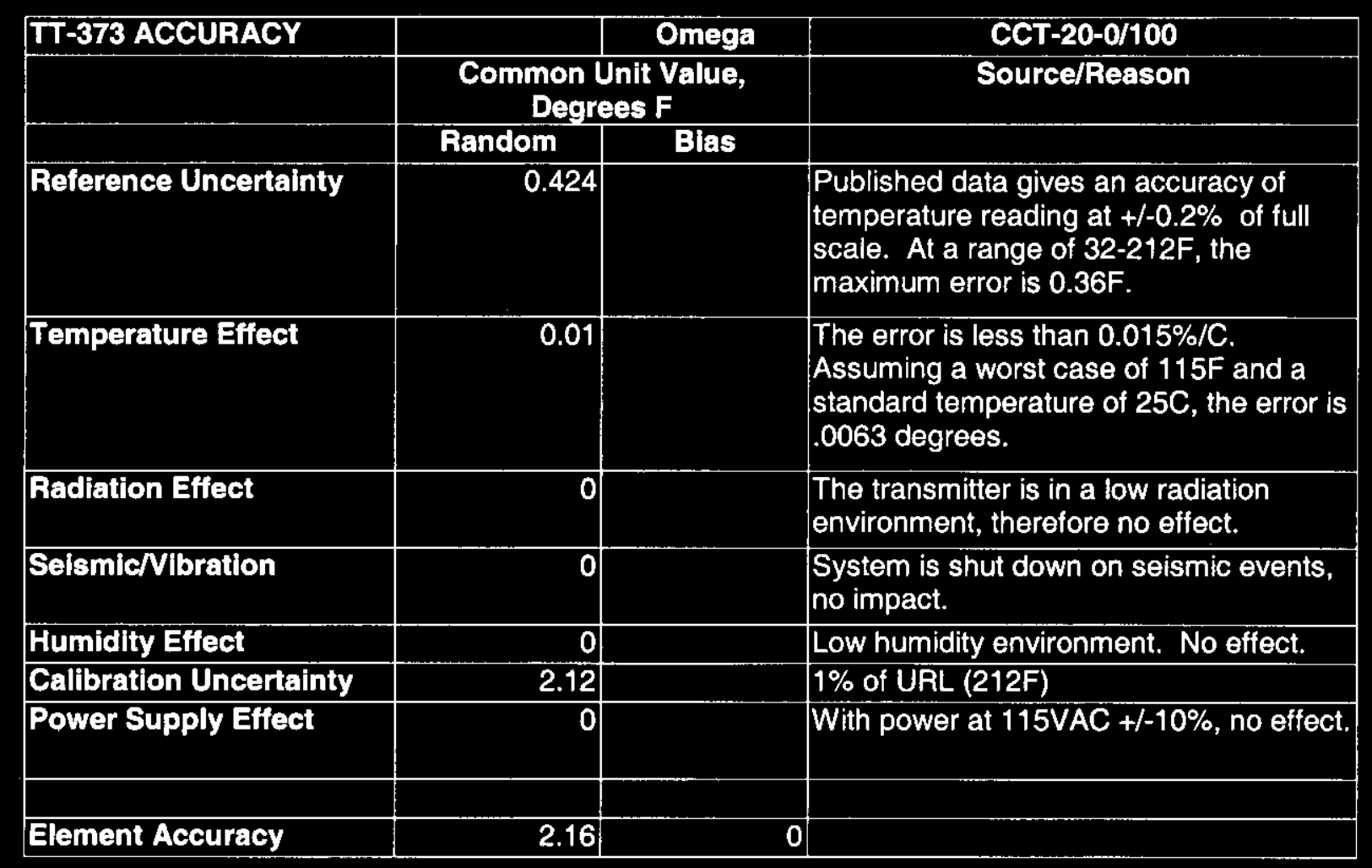


The inaccuracy of SY 101-WT-TI-373 is given below:

\begin{tabular}{|c|c|c|c|}
\hline \multirow[t]{3}{*}{ TI-373 ACCURACY } & & $\begin{array}{c}\text { Newport } \\
\text { Electronics }\end{array}$ & 558B-ET-IS1-SPC18 \\
\hline & \multicolumn{2}{|c|}{$\begin{array}{l}\text { Common Unit Value, } \\
\text { Degrees F }\end{array}$} & Source/Reason \\
\hline & Random & Bias & \\
\hline Reference Uncertainty & 1.212 & & $\begin{array}{l}.1 \% \text { of reading, plus one digit. } \\
\text { Conservatively assumed maximum } \\
\text { temperature of } 212 \mathrm{~F} \text {. }\end{array}$ \\
\hline Temperature Effect & 7.03 & & $\begin{array}{l}\text { The accuracy is based on a } 25 \mathrm{C} \\
\text { temperature. Zero error is }+/-.3 \text { count/C. } \\
\text { Span error is . } 015 \% \text { Span/C. These two } \\
\text { errors can be combined using the square } \\
\text { root of the sum of the squares method. } \\
\text { The } 350 \mathrm{~A} \text { panel is assumed to have a } \\
\text { self heating temperature rise of } 15 \mathrm{~F} \text {. } \\
\text { The Functional Requirements Document } \\
\text { gave an acceptable ambient transfer } \\
\text { temperature range of } 20-100 \mathrm{~F} \text {. The } \\
\text { greatest tempurature difference is } \\
23.33 \mathrm{C} \text {. Based on these extremes and } \\
\text { the equations, a maximum error is } 7.03 \mathrm{~F} \\
\text { and occurs at } 20 \mathrm{~F} \text { with a maximum } \\
\text { temperature of } 212 \mathrm{~F} \text { and a span of } 180 \mathrm{~F} \text {. }\end{array}$ \\
\hline Radiation Effect & 0 & & $\begin{array}{l}\text { The panel meter is located in a low } \\
\text { radiation environment. }\end{array}$ \\
\hline Seismic/VIbration & 0 & & $\begin{array}{l}\text { System is shut down on seismic events, } \\
\text { no impact. }\end{array}$ \\
\hline Humidity Effect & 0 & & $\begin{array}{l}\text { The panel meter is rated for } 95 \% \\
\text { humidity, at } 40 \mathrm{C} \text {. It is located in a low } \\
\text { humidity environment, no effect }\end{array}$ \\
\hline Calibration Uncertainty & 2.12 & & $1.0 \%$ of full scale (212F) \\
\hline Power Supply Effect & 0 & & $\begin{array}{l}\text { As long as within required values on } \\
\text { voltage supply, no effect. }\end{array}$ \\
\hline Element Accuracy & 7.44 & 0 & \\
\hline
\end{tabular}

All of these element inaccuracies are combined to find a loop inaccuracy:

\begin{tabular}{|l|r|c|}
\hline TI-373 Loop Accuracy & & \\
\hline & Value & Units \\
\hline Loop Accuracy & 7.75 & Degrees F \\
\hline Loop Drift & 0.405 & Degrees F \\
\hline Total Loop Uncertainty & 7.76 & Degrees F \\
\hline
\end{tabular}

This indicates that a typical reading of $130^{\circ} \mathrm{F}$ could be in error by $\pm 7.76^{\circ} \mathrm{F}$, or $\pm 5.97 \%$ 
The accuracy of the reading of SY461-WT-TIY-373 is quantified by combining the inaccuracies and drift from each element in the instrument loop. These elements are SY101-WT-TE-373, SY101-WT-TT-373, and SY461-WT-TIY-373. Accuracies of SY101-WT-TE-373, SY101-WT-TT-373 were given above. The accuracy of SY 461-WT-TIY-373 and the combined loop accuracy is established below.

\begin{tabular}{|c|c|c|c|}
\hline TIY-373 ACCURACY & & $\begin{array}{l}\text { Newport } \\
\text { Electronics }\end{array}$ & INFP-0210-C2 \\
\hline & \multicolumn{2}{|c|}{$\begin{array}{c}\text { Common Unit Value, } \\
\text { Degrees F }\end{array}$} & Source/Reason \\
\hline & Random & Bias & \\
\hline Reference Uncertainty & 0.0106 & & $\begin{array}{l}.005 \% \text { of reading. Maximum value of } \\
212 \mathrm{~F} \text { used. }\end{array}$ \\
\hline Temperature Effect & 0.00 & & $\begin{array}{l}\text { The accuracy is based on a } 25 \mathrm{C} \\
\text { temperature. Span error is } 20 \mathrm{ppm} / \mathrm{C} \text {. } \\
\text { The } 350 \mathrm{~B} \text { panel is assumed to have a } \\
\text { maximum temperature of } 92 \mathrm{~F} \text {, or } 8.33 \mathrm{C} \\
\text { above } 25 \mathrm{C} \text {. The error is expected to be } \\
\text { no greater than } 0.0002 \mathrm{~F}\end{array}$ \\
\hline Radiation Effect & 0 & & $\begin{array}{l}\text { DACs is a low radiation environment, no } \\
\text { effect anticipated. }\end{array}$ \\
\hline Seismic/Vibration & 0 & & $\begin{array}{l}\text { System is shut down on seismic events, } \\
\text { no impact. }\end{array}$ \\
\hline Humidity Effect & 0 & & $\begin{array}{l}\text { Device is rated for } 95 \% \text { non condensing } \\
\text { at } 40 \mathrm{C} \text {. Low Humidity environment, no } \\
\text { effect. }\end{array}$ \\
\hline Calibration Uncertainty & 2.12 & & $1 \%$ of full scale \\
\hline Power Supply Effect & 0 & & $\begin{array}{l}\text { As long as within required values on } \\
\text { voltage supply, no effect. Voltage range } \\
\text { for the instrument is } 115 \mathrm{~V}+/-10 \% \text { and } 49 \\
\text { to } 100 \mathrm{~Hz} \text {. }\end{array}$ \\
\hline Element Accuracy & 2.12 & $\underline{0}$ & \\
\hline
\end{tabular}

All of these element inaccuracies are combined to find a loop inaccuracy:

\begin{tabular}{|l|r|l|}
\hline TIY-373 Loop Accuracy & & \\
\hline & \multicolumn{1}{|c|}{ Value } & Units \\
\hline Loop Accuracy & 3.03 & Degrees F \\
\hline Loop Drift & 0.405 & Degrees F \\
\hline Total Loop Uncertainty & 3.06 & Degrees F \\
\hline
\end{tabular}

This indicates that a typical reading of $130^{\circ} \mathrm{F}$ could be in error by $\pm 3.06^{\circ} \mathrm{F}$, or $\pm 2.35 \%$ 
From the above, the alarm setpoints for SY101-WT-TAL-373A and SY461-WT-TAL-373B are established below:

\begin{tabular}{|l|r|l|}
\hline TAL-373A Setpoint & & \\
\hline Alarm Point & \multicolumn{1}{|c|}{ Value } & Units \\
\hline Loop Uncertainty & 110 & Degrees F \\
\hline Margin & 3.06 & Degrees F \\
\hline Setpoint & 1 & Degrees F \\
\hline & 114.06 & Degrees F \\
\hline TAL-373B Setpoint & & \\
\hline & & \\
\hline Alarm Point & 110 & Degrees F \\
\hline Loop Uncertainty & 3.06 & Degrees F \\
\hline Margin & 1 & Degrees F \\
\hline Setpoint & 114.06 & Degrees F \\
\hline
\end{tabular}

\subsubsection{LOOP 401}

\section{LOOP DESCRIPTION}

This loop is intended to maintain the temperature in the water support skid electrical enclosure, POR32RW-CP-401, at an acceptable level. Cooling of the cabinets, particularly in the summer, is the primary concern. Because of the self heating of all the electrical equipment within the enclosure, it is not necessary to provide additional heating, even in winter. The loop consists of two elements, a sensor, POR32-RWTC-401, and a fan, POR32-RW-AC-40I. When the sensor reaches a preset temperature of $85^{\circ} \mathrm{F}$, the sensor allows power to go to the fan, providing forced convective cooling of the components within the cabinet. Both of these elements are found within POR32-RW-CP-401.

\section{SETPOINT BASIS}

This setpoint was established by the supplier of the water skid control panel, HiLine Engineering, and is intended to maintain the panel temperatures such that the electronic instrumentation and indication is able to properiy function.

\section{SETPOINT VALUES}

The setpoint is established by HiLine and is deemed adequate. This loop is not going to be calibrated or maintained.

\subsubsection{LOOP 410}

\section{LOOP DESCRIPTION}

This is an indicating and control loop consisting of two elements. The sensing element, POR32-RW-TE410 is a type " $\mathrm{J}$ " thermocouple, affixed to the inlet hose. The temperature indicating controller, POR32RW-TIC-410, is mounted in the water support skid electrical enclosure, POR32-RW-CP-401.

The temperature in the water line is detected by POR32-RW-TE-410, which develops a voltage potential, proportional to the temperature. This potential is detected by POR32-RW-TIC-410, which converts that signal into a digital output. POR32-RW-TIC-410 also attempts to maintain the temperature at a setpoint, developed below. 


\section{SETPOINT BASIS}

The dilution water temperature is to range between $110^{\circ} \mathrm{F}$ and $130^{\circ} \mathrm{F}$ (Process Control Plan, HNF-4264, Rev. 0, Section 2.1.1).

\section{SETPOINT VALUES}

The dilution water temperature at the inlet to the water skid is to be displayed on and POR32-RW-TIC-410. To that end, the range of this indicator must envelop the anticipated water temperature. Temperature indicator POR32-RW-TIC-410 has been set to a range of $0^{\circ} \mathrm{F}$ to $212^{\circ} \mathrm{F}$, which envelops the anticipated operating conditions.

The accuracy of the reading is a function of the error found in POR32-RW-TE-410 and POR32-RW-TIC410. Each element accuracy is developed below, followed by the loop accuracy.

The accuracy of POR32-RW-TE-410 is as follows:

\begin{tabular}{|c|c|c|c|}
\hline TE-410 ACCURACY & & $\begin{array}{c}\text { Cobra Wirer } \\
\text { and Cable }\end{array}$ & jl6spfa-alpfa \\
\hline & $\begin{array}{r}\text { Common l } \\
\text { Degre }\end{array}$ & $\begin{array}{l}\text { Unit Value, } \\
\text { ees F }\end{array}$ & Source/Reason \\
\hline & Random & Blas & \\
\hline Reference Uncertainty & 5.9 & 7.5 & $\begin{array}{l}\text { Random- The accuracy of a } \\
\text { thermocouple is within } 1 \% \text { of the } \\
\text { absolute temperature. At } 130 \mathrm{~F} \text {, this is } \\
5.9 \mathrm{~F} \\
\text { Each connecting jack is assumed to act } \\
\text { as a cold junction with an error of } 2.5 \mathrm{~F} \\
\text { per junction. An assumed } 3 \text { junctions } \\
\text { exist for this element. }\end{array}$ \\
\hline Temperature Effect & 0.00 & & $\begin{array}{l}\text { This is a temperature sensing device, no } \\
\text { effect }\end{array}$ \\
\hline Radlation Effect & 0 & & $\begin{array}{l}\text { Located in a low radiation environment, } \\
\text { no effect. }\end{array}$ \\
\hline Selsmic/Vibration & 0 & & $\begin{array}{l}\text { System is shut down on seismic events, } \\
\text { no impact. }\end{array}$ \\
\hline Humidity Effect & 0 & & No effect. \\
\hline Calibration Uncertainty & 0 & & Non calibratable device. \\
\hline Power Supply Effect & 0 & & Self powered, no effect. \\
\hline Element Accuracy & 5.90 & 7.5 & \\
\hline
\end{tabular}


The accuracy of POR32-RW-TIC-410 is as follows:

\begin{tabular}{|c|c|c|c|}
\hline \multirow[t]{3}{*}{ TIC-410 ACCURACY } & & Watlow & \multirow{2}{*}{$\begin{array}{c}\text { V4TH-CDAA-AARG } \\
\text { Source/Reason }\end{array}$} \\
\hline & \multicolumn{2}{|c|}{$\begin{array}{l}\text { Common Unit Value, } \\
\text { Degrees F }\end{array}$} & \\
\hline & Random & Bias & \\
\hline Reference Uncertainty & 1.35 & & $\begin{array}{l}\text { Published data gives an accuracy of }+/- \\
0.1 \% \text { of span. The span for a type } \mathrm{J} \\
\text { thermocouple is } 1350 \mathrm{~F} \text {, so an error of up } \\
\text { to } 1.35 \mathrm{~F} \text { can be expected. }\end{array}$ \\
\hline Temperature Effect & 6.60 & & $\begin{array}{l}\text { Accuracy is given for } 77 \mathrm{~F} \text {. The } \\
\text { maximum temperature in the panel is } \\
\text { assumed to be } 110 \mathrm{~F} \text {. The temperature } \\
\text { effect is }+/-0.2 \mathrm{~F} / \mathrm{F} \text {. }\end{array}$ \\
\hline Radiation Effect & 0 & & $\begin{array}{l}\text { The indicator is in a low radiation } \\
\text { environment. No effect. }\end{array}$ \\
\hline Seismic/V/bration & 0 & & $\begin{array}{l}\text { System is shut down on seismic events, } \\
\text { no impact. }\end{array}$ \\
\hline Humidity Effect & 0 & & Low humidity environment. No effect. \\
\hline Calibration Uncertainty & 9 & & $5 \%$ of calibration scale $(32-212 F, 180 F)$ \\
\hline Power Supply Effect & 0 & & No data available, no anticipated effect. \\
\hline Element Accuracy & 11.24 & & \\
\hline
\end{tabular}

The loop accuracy as displayed on POR32-RW-TIC-410 is:

\begin{tabular}{|l|r|l|}
\hline TIC-410 Loop Accuracy & & \\
\hline & Value & Units \\
\hline Loop Accuracy & 20.20 & Degrees F \\
\hline Loop Drift & 0 & Degrees F \\
\hline Total Loop Uncertainty & 27.70 & Degrees F \\
\hline
\end{tabular}

This value of $\pm 27.7^{\circ} \mathrm{F}$ at a nominal value of $130^{\circ} \mathrm{F}$ is an error of $\pm 21.31 \%$.

The critical value is for the waste solution to remain above the temperature where precipitation of solids might occur. This point is approximately $110^{\circ} \mathrm{F}$. The setpoint will be placed above that value by a margin and all estimated errors. The control setpoint for POR32-RW-TIC-410 is established as follows:

\begin{tabular}{|l|r|l|}
\hline TIC-410 Setpoint & & \\
\hline & Value & Units \\
\hline Alarm Point & 110 & Degrees F \\
\hline Loop Uncertainty & 27.70 & Degrees F \\
\hline Margin & 1 & Degrees F \\
\hline Setpoint & 138.70 & Degrees F \\
\hline
\end{tabular}




\subsubsection{LOOP 411}

\section{LOOP DESCRIPTION}

This loop consists of a controller, POR32-RW-TC-411, and two sensing elements, POR32-RW-TE-411A and POR32-RW-TE-411B. There are actually two independent loops. The first is the control loop consisting of POR32-RW-TC-411 and POR32-RW-TE-411A. The temperature of the tank surface is sensed by the capillary tube sensor, POR32-RW-TE-411A, which transmits a pressure to the POR32-RWTC-411. The controller energizes/de-energizes the heat trace depending upon the sensed temperature and the setpoint.

The second loop is to prevent damage to the fiberglass tank by shutting off the heat trace if it gets to a predetermined temperature. That temperature is sensed by the capillary tube sensor, POR32-RW-TE-411B, which transmits a pressure to the POR32-RW-TC-411. The controller de-energizes the heat trace depending upon reaching and the setpoint.

\section{SETPOINT BASIS}

The dilution water temperature is to range between $110^{\circ} \mathrm{F}$ and $130^{\circ} \mathrm{F}$ (Process Control Plan, HNF-4264, Rev. 0, Section 2.1.1). In addition, by engineering judgement, the tank must be kept below $140^{\circ} \mathrm{F}$ as a system protection value.

\section{SETPOINT VALUES}

\section{Temperature Control}

The critical value is for the waste solution to remain above the temperature where precipitation of solids might occur. This point is approximately $110^{\circ} \mathrm{F}$. The control setpoint will be placed above that value by a margin and all estimated errors. The control setpoint for POR32-RW-TC-411 must incorporate all the errors for the entire loop. This is established by combining the errors of each element.

The error of POR32-RW-TE-411A is calculated as follows:

\begin{tabular}{|c|c|c|c|}
\hline TE-411A AOCURACY & & Jualn & UE-55 \\
\hline & $\begin{array}{r}\text { Common } \\
\text { Degt }\end{array}$ & mifyo, & Source/feason \\
\hline & Ranoom & $7 x=15$ & \\
\hline Reference Unceralnty & 39 & 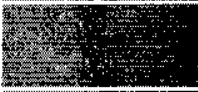 & $\begin{array}{l}+/-3 \% \text { of reading at mid } 50 \% \text { range. } \\
\text { Typical reading is } 130 F \text {. }\end{array}$ \\
\hline Temperature Eneat & 000 & 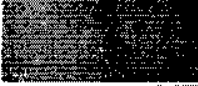 & $\begin{array}{l}\text { This is a temperature sensing device, no } \\
\text { effect }\end{array}$ \\
\hline Radlation Efieot & & the & $\begin{array}{l}\text { Located in a low radiation environment, } \\
\text { no effect. }\end{array}$ \\
\hline Selsmianibration & & 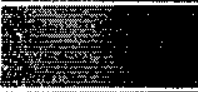 & $\begin{array}{l}\text { System is shut down on seismic events, } \\
\text { no impact. }\end{array}$ \\
\hline Humidiy sifeet & $=0$ & W & No effect: \\
\hline Callbration Unesranty & $5=0$ & Stres & Non calibratible device. \\
\hline Powar Supply Enect & 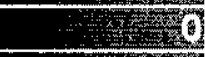 & The & Self powered, no elfect. \\
\hline & -8 & 20 & \\
\hline Element Accuracy & 300 & 8 & \\
\hline
\end{tabular}

For information only, pending completion of techinical review. 
The accuracy of POR32-RW-TC-411 is given below:

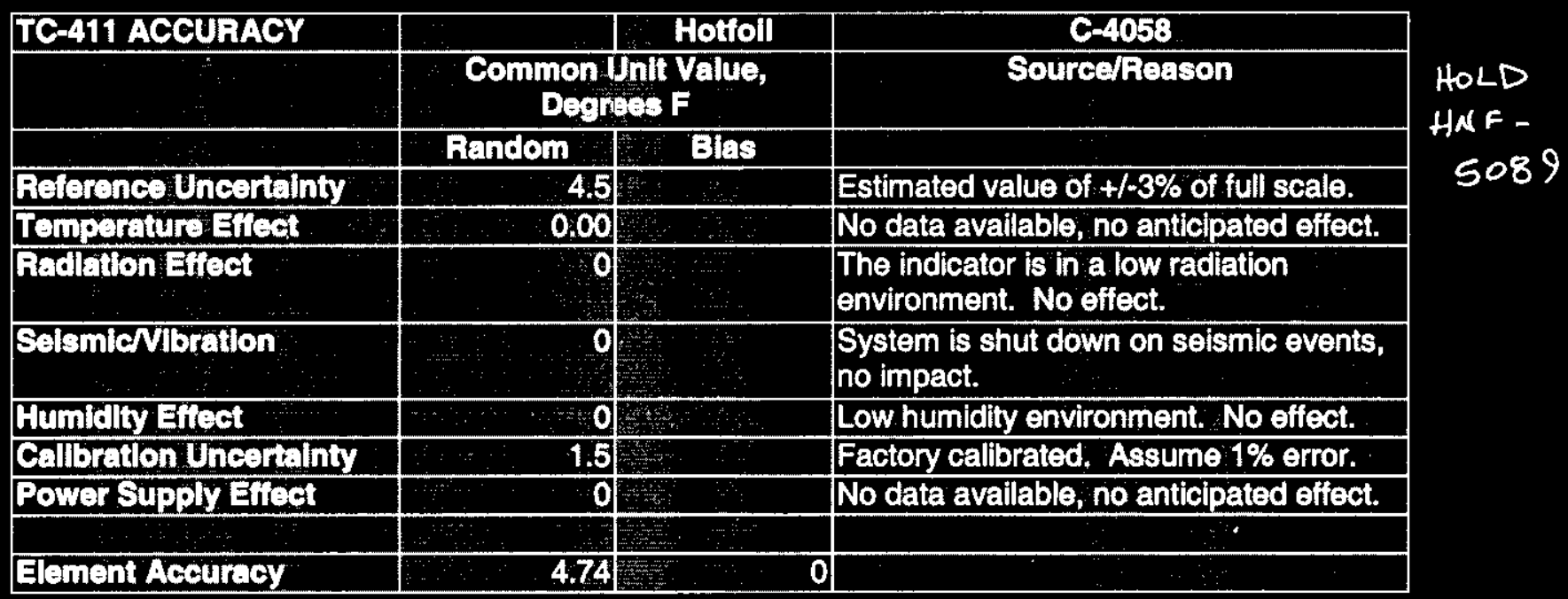

For information only, pending completion of technical review.

The loop accuracy is developed below:

\begin{tabular}{|l|r|r|}
\hline $\begin{array}{c}\text { TC-411 Loop Accuracy, } \\
\text { for control }\end{array}$ & \\
\hline & Value & \\
\hline Loop Accuracy & 6.14 & Dogles \\
\hline Loop Drit & 0 & Dogress F \\
\hline Total Loop Uncertainty & 6.14 & Dogress F \\
\hline
\end{tabular}

HOL D

HNF -5089

For information only, pending completion of technical review.

Based on the low temperature limitation and the uncertainty, a setpoint can be established as follows:

\begin{tabular}{|c|c|c|}
\hline TC-41 Control Solpolnt & & \\
\hline- & Value & Unto \\
\hline Alampolnt & 110 & Daghos F \\
\hline Loop Uhooralnty & 614 & Dogless F \\
\hline Wargh & 10 & Eogioes F \\
\hline Setpolnt & 126.14 & Doglobs F \\
\hline
\end{tabular}

HoLD

HNF- 5089

For information only, pending completion of tedifical review.

\section{High Temperature Shut Off}

The critical value is to remain below the critical value for the fiberglass tank. This point is approximately $140^{\circ} \mathrm{F}$. The shut off setpoint will be placed below that value by a margin and all estimated errors. The errors for this loop are identical to those for the temperature control loop. 
The high temperature shut off setpoint is given as follows:

\begin{tabular}{|l|r|l|}
\hline TC-411 Shut Oif Setpolnt & & \multicolumn{1}{|c|}{} \\
\hline & Value & Units \\
\hline Alarm Polnt & 140 & Dogrees F \\
\hline Loop Uncertainty & 6.14 & Degrees F \\
\hline Margin & 0 & Degrees F \\
\hline Setpolnt & 133.86 & Degrees F \\
\hline
\end{tabular}

For information only, pending completion of technical review.

\subsubsection{LOOP 412}

\section{LOOP DESCRIPTION}

This is a simple indication loop to provide the operator the temperature of the water in the tank. It consists of a sensing element, POR32-RW-TE-412, a type "J" thermocouple, submersed in TK-401. The temperature indicator, POR32-RW-TI-412, is mounted in the water support skid electrical enclosure, POR32-RW-CP-401.

The temperature in the tank is detected by POR32-RW-TE-412, which develops a voltage potential proportional to the temperature. This potential is detected by POR32-RW-TI-412, which converts that signal into a digital output.

\section{SETPOINT BASIS}

The dilution water temperature is to range between $110^{\circ} \mathrm{F}$ and $130^{\circ} \mathrm{F}$ (Process Control Plan, HNF-4264, Rev. 0, Section 2.1.1).

\section{SETPOINT VALUES}

The dilution water temperature in TK-401 is to be displayed on and POR32-RW-TI-412. To that end, the range of this indicator must envelop the anticipated water temperature. Temperature indicator POR32-RWTI- 412 has been set to a range of $0^{\circ} \mathrm{F}$ to $212^{\circ} \mathrm{F}$, which envelops the anticipated operating conditions.

The accuracy of the reading is a function of the error found in POR32-RW-TE-412 and POR32-RW-TI412. Each element accuracy is developed below, followed by the loop accuracy. 
The accuracy of POR32-RW-TE-412 is as follows:

\begin{tabular}{|c|c|c|c|}
\hline TE-412 ACCURACY & & Watlow & AFGMOTFXXXVJ300 \\
\hline & $\begin{array}{r}\text { Common U } \\
\text { Degre }\end{array}$ & $\begin{array}{l}\text { Value, } \\
\text { F }\end{array}$ & Source/Reason \\
\hline & Random & Bias & \\
\hline Reference Uncertainty & 5.9 & 7.5. & $\begin{array}{l}\text { Random- The accuracy of a } \\
\text { thermocouple is within } 1 \% \text { of the } \\
\text { absolute temperature. At } 130 \mathrm{~F} \text {, this is } \\
5.9 \mathrm{~F} \\
\text { Bias- } \\
\text { Each connecting jack is assumed to act } \\
\text { as a cold junction with an error of } 2.5 \mathrm{~F} \\
\text { per junction. An assumed } 3 \text { junctions } \\
\text { exist for this element. }\end{array}$ \\
\hline Temperature Effect & 0.00 & & $\begin{array}{l}\text { This is a temperature sensing device, no } \\
\text { effect }\end{array}$ \\
\hline Radiation Effect & 0 & & $\begin{array}{l}\text { Located in a low radiation environment, } \\
\text { no effect. }\end{array}$ \\
\hline Seismic/Nbration & 0 & & $\begin{array}{l}\text { System is shut down on seismic events, } \\
\text { no impact. }\end{array}$ \\
\hline Humidity Effect & 0 & & No effect. \\
\hline Callbration Uncertainty & 0 & & Non calibratable device. \\
\hline Power Supply Effect & 0 & & Self powered, no effect. \\
\hline Element Accuracy & 5.90 & 7.5 & \\
\hline
\end{tabular}

The accuracy of POR32-RW-TI-412 is as follows:

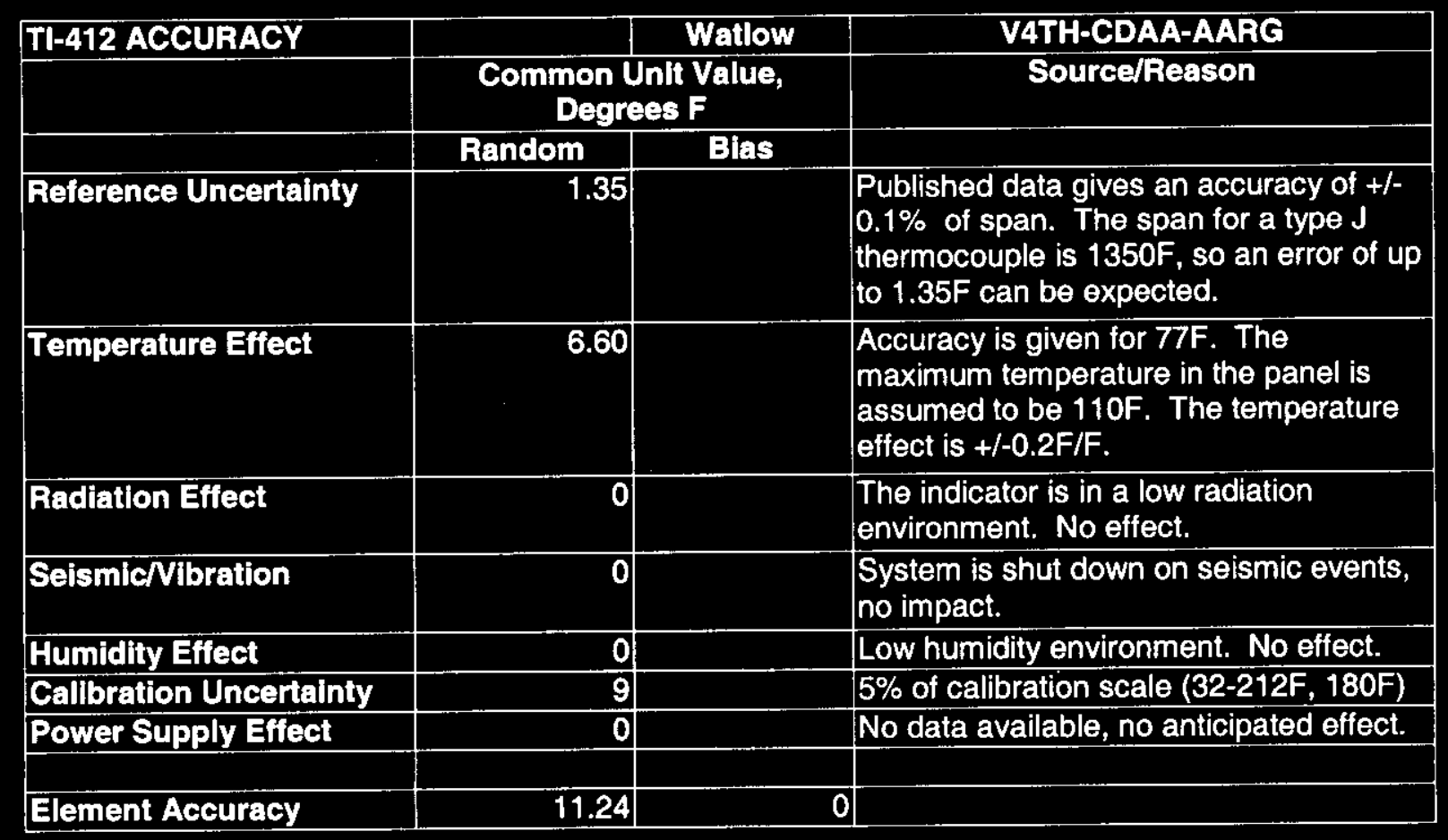


The loop accuracy as displayed on POR32-RW-TI-412 is:

\begin{tabular}{|l|r|l|}
\hline Tl-412 Loop Accuracy & & \\
\hline & Value & Units \\
\hline Loop Accuracy & 20.20 & Degrees F \\
\hline Loop Drift & 0 & Degrees F \\
\hline Total Loop Uncertainty & 27.70 & Degrees F \\
\hline
\end{tabular}

This value of $\pm 27.7^{\circ} \mathrm{F}$ at a nominal value of $130^{\circ} \mathrm{F}$ is an error of $\pm 21.31 \%$.

\subsubsection{LOOP 413}

\section{LOOP DESCRIPTION}

This is an indicating and control loop consisting of two elements. The sensing element, POR32-RW-TE413 is a type " $\mathrm{J}$ " thermocouple, affixed to the inlet hose. The temperature indicating controller, POR32RW-TIC-413, is mounted in the water support skid electrical enclosure, POR32-RW-CP-401.

The temperature in the water line is detected by POR32-RW-TE-413, which develops a voltage potential, proportional to the temperature. This potential is detected by POR32-RW-TIC-413, which converts that signal into a digital output. POR32-RW-TIC-413 also attempts to maintain the temperature at a setpoint, developed below.

\section{SETPOINT BASIS}

The dilution water temperature is to range between $110^{\circ} \mathrm{F}$ and $130^{\circ} \mathrm{F}$ (Process Control Plan, HNF-4264, Rev. 0, Section 2.1.1).

\section{SETPOINT VALUES}

The dilution water temperature at the inlet to the water skid is to be displayed on and POR32-RW-TIC-413. To that end, the range of this indicator must envelop the anticipated water temperature. Temperature indicator POR32-RW-TIC-413 has been set to a range of $0^{\circ} \mathrm{F}$ to $212^{\circ} \mathrm{F}$, which envelops the anticipated operating conditions.

The accuracy of the reading is a function of the error found in POR32-RW-TE-413 and POR32-RW-TIC413. Each element accuracy is developed below, followed by the loop accuracy. 
The accuracy of POR32-RW-TE-413 is as follows:

\begin{tabular}{|c|c|c|c|}
\hline \multirow[t]{3}{*}{ TE-413 ACCURACY } & & Watlow & \multirow{3}{*}{$\begin{array}{l}72 X \text { JWGBO12 } \\
\text { Source/Reason }\end{array}$} \\
\hline & \multicolumn{2}{|c|}{$\begin{array}{l}\text { Common Unit Value, } \\
\text { Degrees F }\end{array}$} & \\
\hline & Random & Bias & \\
\hline Reference Uncertainty & 5.9 & 7.5 & $\begin{array}{l}\text { Random- The accuracy of a } \\
\text { thermocouple is within } 1 \% \text { of the } \\
\text { absolute temperature. At } 130 \mathrm{~F} \text {, this is } \\
5.9 \mathrm{~F} \\
\text { Each connecting jack is assumed to act } \\
\text { as a cold junction with an error of } 2.5 \mathrm{~F} \\
\text { per junction. An assumed } 3 \text { junctions } \\
\text { exist for this element. }\end{array}$ \\
\hline Temperature Effect & 0.00 & & $\begin{array}{l}\text { This is a temperature sensing device, no } \\
\text { effect }\end{array}$ \\
\hline Radlation Effect & 0 & & $\begin{array}{l}\text { Located in a low radiation environment, } \\
\text { no effect. }\end{array}$ \\
\hline Seismic/Vibration & 0 & & $\begin{array}{l}\text { System is shut down on seismic events, } \\
\text { no impact. }\end{array}$ \\
\hline Humidity Effect & 0 & & No effect. \\
\hline Calibratlon Uncertainty & 0 & & Non calibratable device. \\
\hline Power Supply Effect & 0 & & Self powered, no effect. \\
\hline Element Accuracy & 5.90 & 7.5 & \\
\hline
\end{tabular}

The accuracy of POR32-RW-TIC-410 is as follows:

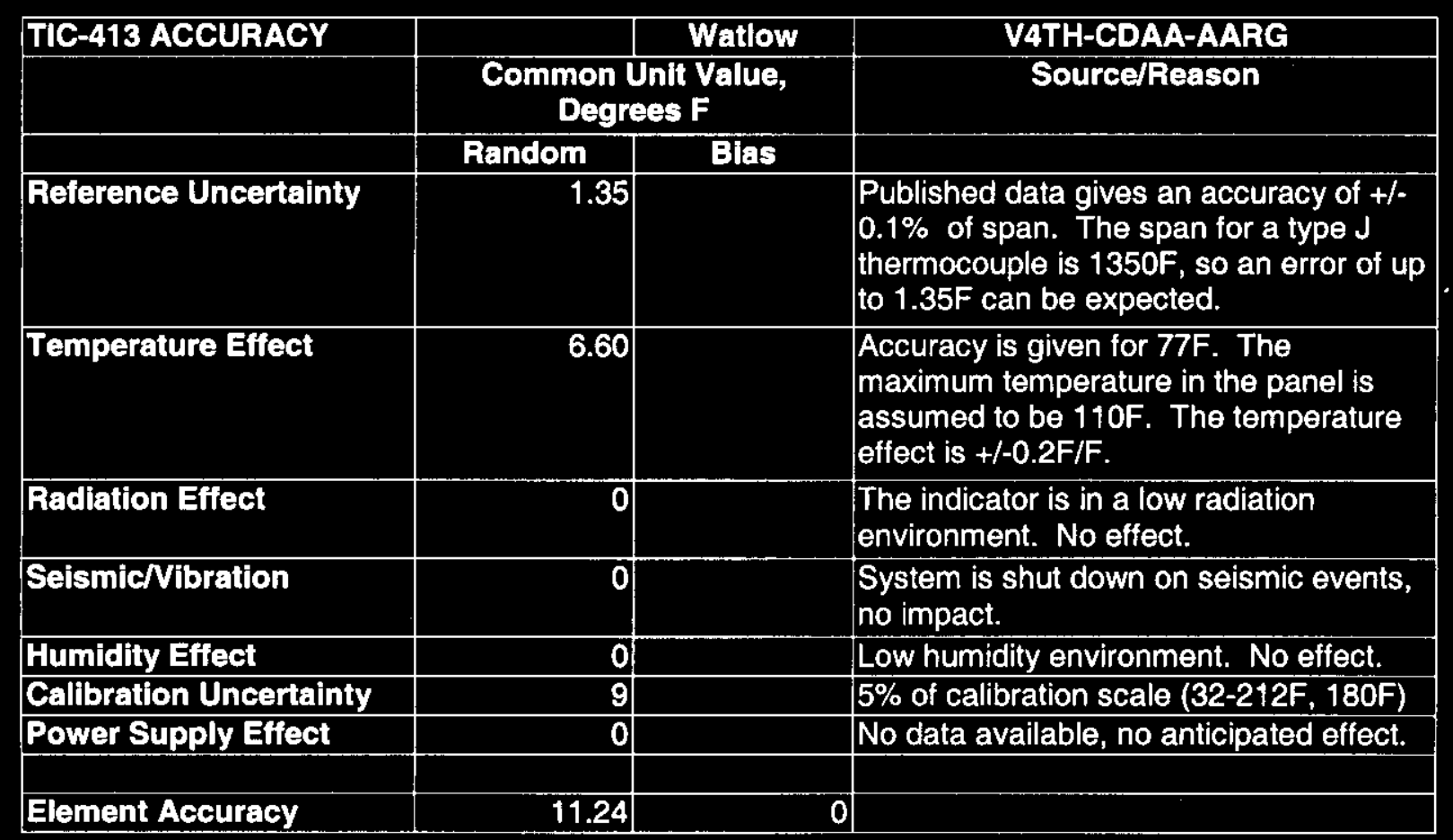


The loop accuracy as displayed on POR32-RW-TIC-413 is:

\begin{tabular}{|l|r|c|}
\hline TIC-413 Loop Accuracy & & \\
\hline & Value & Units \\
\hline Loop Accuracy & 20.20 & Degrees F \\
\hline Loop Drift & 0 & Degrees F \\
\hline Total Loop Uncertainty & 27.70 & Degrees F \\
\hline
\end{tabular}

This value of $\pm 27.7^{\circ} \mathrm{F}$ at a nominal value of $130^{\circ} \mathrm{F}$ is an error of $\pm 21.31 \%$.

The critical value is for the waste solution to remain above the temperature where precipitation of solids might occur. This point is approximately $110^{\circ} \mathrm{F}$. The setpoint will be placed above that value by a margin and all estimated errors. The control setpoint for POR32-RW-TIC-413 is established as follows:

\begin{tabular}{|l|r|l|}
\hline TIC-413 Setpoint & & \\
\hline & Value & Units \\
\hline Alarm Point & 110 & Degrees F \\
\hline Loop Uncertainty & 27.70 & Degrees F \\
\hline Margin & 1 & Degrees F \\
\hline Setpoint & 138.70 & Degrees F \\
\hline
\end{tabular}

\subsubsection{LOOP 414}

\section{LOOP DESCRIPTION}

This is an indicating and control loop consisting of two elements. The sensing element, POR32-RW-TE414 is a type " $\mathrm{J}$ " thermocouple, affixed ACC-401. The temperature indicating controller, POR32-RWTIC-414, is mounted in the water support skid electrical enclosure, POR32-RW-CP-401.

The temperature in the accumulator is detected by POR32-RW-TE-414, which develops a voltage potential, proportional to the temperature. This potential is detected by POR32-RW-TIC-414, which converts that signal into a digital output. POR32-RW-TIC-414 also attempts to maintain the temperature at a setpoint, developed below.

\section{SETPOINT BASIS}

The dilution water temperature is to range between $110^{\circ} \mathrm{F}$ and $130^{\circ} \mathrm{F}$ (Process Control Plan, HNF-4264, Rev. 0, Section 2.1.1).

\section{SETPOINT VALUES}

The dilution water temperature at the inlet to the water skid is to be displayed on and POR32-RW-TIC-414. To that end, the range of this indicator must envelop the anticipated water temperature. Temperature indicator POR32-RW-TIC-414 has been set to a range of $0^{\circ} \mathrm{F}$ to $212^{\circ} \mathrm{F}$, which envelops the anticipated operating conditions.

The accuracy of the reading is a function of the error found in POR32-RW-TE-414 and POR32-RW-TIC414. Each element accuracy is developed below, followed by the loop accuracy. 
The accuracy of POR32-RW-TE-414 is as follows:

\begin{tabular}{|c|c|c|c|}
\hline \multirow[t]{3}{*}{ TE-414 ACCURACY } & & Watlow & \multirow{3}{*}{$\begin{array}{l}\text { 70XJTUD012 } \\
\text { Source/Reason }\end{array}$} \\
\hline & \multicolumn{2}{|c|}{$\begin{array}{c}\text { Common Unit Value, } \\
\text { Degrees F }\end{array}$} & \\
\hline & Random & Bias & \\
\hline Reference Uncertainty & 5.9 & & $\begin{array}{l}\text { Random- The accuracy of a } \\
\text { thermocouple is within } 1 \% \text { of the } \\
\text { absolute temperature. At } 130 \mathrm{~F} \text {, this is } \\
5.9 \mathrm{~F} \\
\text { Each connecting jack is assumed to act } \\
\text { as a cold junction with an error of } 2.5 \mathrm{~F} \\
\text { per junction. An assumed } 3 \text { junctions } \\
\text { exist for this element. }\end{array}$ \\
\hline Temperature Effect & 0.00 & & $\begin{array}{l}\text { This is a temperature sensing device, no } \\
\text { effect }\end{array}$ \\
\hline Radiation Effect & 0 & & $\begin{array}{l}\text { Located in a low radiation environment, } \\
\text { no effect. }\end{array}$ \\
\hline Seismic/Vlbration & 0 & & $\begin{array}{l}\text { System is shut down on seismic events, } \\
\text { no impact. }\end{array}$ \\
\hline Humidity Effect & 0 & & No effect. \\
\hline Calibration Uncertainty & 0 & & Non calibratable device. \\
\hline Power Supply Effect & 0 & & Self powered, no effect. \\
\hline Element Accuracy & 5.90 & 7.5 & \\
\hline
\end{tabular}

The accuracy of POR32-RW-TIC-414 is as follows:

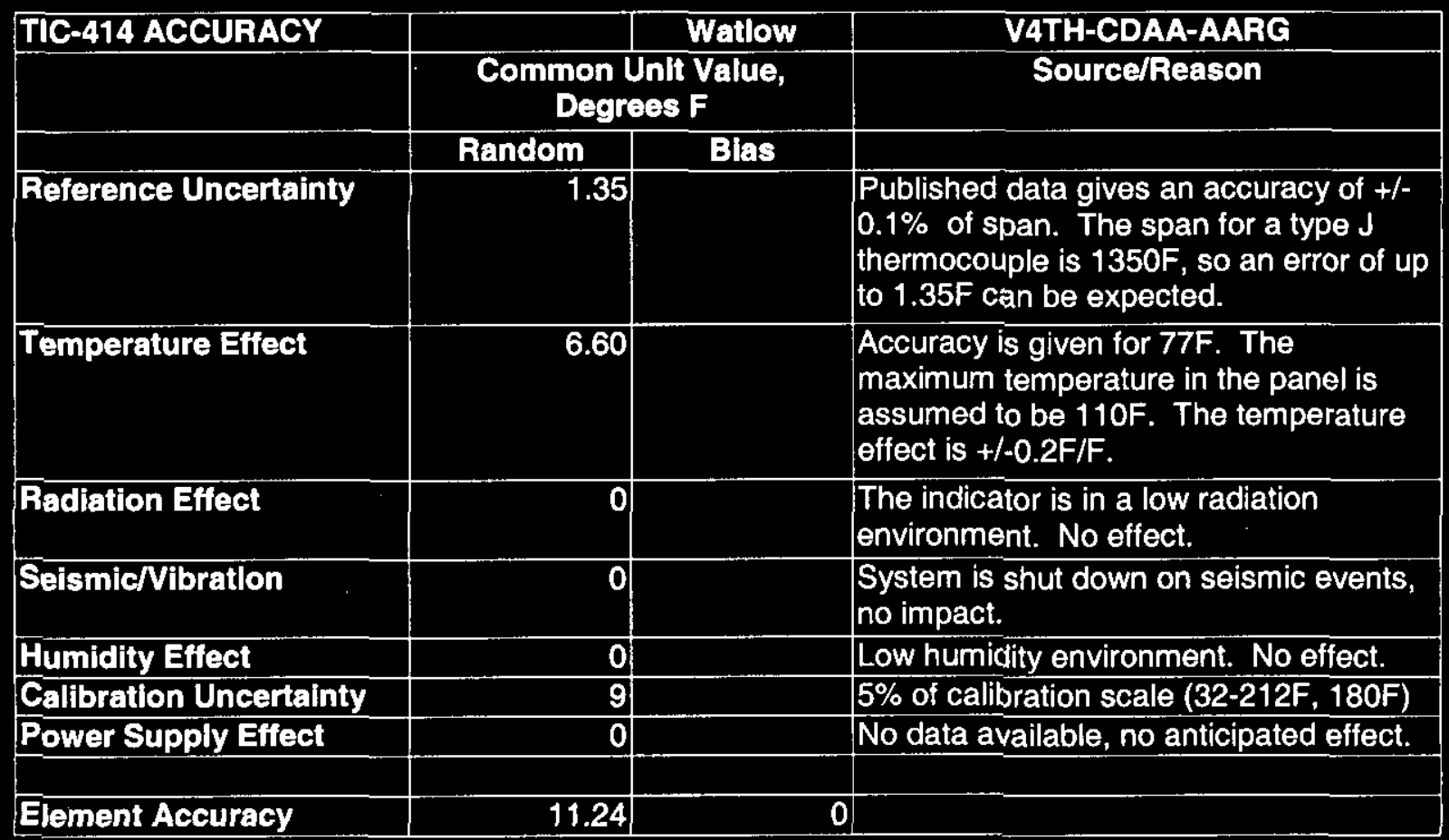


The loop accuracy as displayed on POR32-RW-TIC-414 is:

\begin{tabular}{|l|r|l|}
\hline TIC-414 Loop Accuracy & & \\
\hline & Value & Units \\
\hline Loop Accuracy & 20.20 & Degrees F \\
\hline Loop Drift & 0 & Degrees F \\
\hline Total Loop Uncertainty & 27.70 & Degrees F \\
\hline
\end{tabular}

This value of $\pm 27.7^{\circ} \mathrm{F}$ at a nominal value of $130^{\circ} \mathrm{F}$ is an error of $\pm 21.31 \%$.

The critical yalue is for the waste solution to remain above the temperature where precipitation of solids might occur. This point is approximately $110^{\circ} \mathrm{F}$. The setpoint will be placed above that value by a margin and all estimated errors. The control setpoint for POR32-RW-TIC-414 is established as follows:

\begin{tabular}{|l|r|c|}
\hline TIC-414 Setpoint & & \\
\hline & \multicolumn{1}{|c|}{ Value } & Units \\
\hline Alarm Point & 110 & Degrees F \\
\hline Loop Uncertainty & 27.70 & Degrees F \\
\hline Margin & 1 & Degrees F \\
\hline Setpoint & 138.70 & Degrees F \\
\hline
\end{tabular}

\subsubsection{LOOP 415}

\section{LOOP DESCRIPTION}

This is an indicating and control loop consisting of two elements. The sensing element, POR32-RW-TE410 is a type "l" thermocouple, affixed to the outlet hose. The temperature indicating controller, POR32RW-TIC-415, is mounted in the water support skid electrical enclosure, POR32-RW-CP-401.

The temperature in the water line is detected by POR32-RW-TE-415, which develops a voltage potential, proportional to the temperature. This potential is detected by POR32-RW-TIC-415, which converts that signal into a digital output. POR32-RW-TIC-415 also attempts to maintain the temperature at a setpoint, developed below.

\section{SETPOINT BASIS}

The dilution water temperature is to range between $110^{\circ} \mathrm{F}$ and $130^{\circ} \mathrm{F}$ (Process Control Plan, HNF-4264, Rev. 0, Section 2.1.1).

\section{SETPOINT VALUES}

The dilution water temperature at the outlet to the water skid is to be displayed on and POR32-RW-TIC415. To that end, the range of this indicator must envelop the anticipated water temperature. Temperature indicator POR32-RW-TIC- 415 has been set to a range of $0^{\circ} \mathrm{F}$ to $212^{\circ} \mathrm{F}$, which envelops the anticipated operating conditions.

The accuracy of the reading is a function of the error found in POR32-RW-TE-415 and POR32-RW-TIC415. Each element accuracy is developed below, followed by the loop accuracy. 
The accuracy of POR32-RW-TE-415 is as follows:

\begin{tabular}{|c|c|c|c|}
\hline TE-415 ACCURACY & & $\begin{array}{l}\text { Cobra Wirer } \\
\text { and Cable }\end{array}$ & jl6spfa-alpfa \\
\hline & $\begin{array}{r}\text { Common } \mathrm{U} \\
\text { Degre }\end{array}$ & $\begin{array}{l}\text { Jnit Value, } \\
\text { ees F }\end{array}$ & Source/Reason \\
\hline & Random & Bias & \\
\hline Reference Uncertainty & 5.9 & 7.5 & $\begin{array}{l}\text { Random- The accuracy of a } \\
\text { thermocouple is within } 1 \% \text { of the } \\
\text { absolute temperature. At } 130 \mathrm{~F} \text {, this is } \\
5.9 \mathrm{~F} \\
\text { Each connecting jack is assumed to act } \\
\text { as a cold junction with an error of } 2.5 \mathrm{~F} \\
\text { per junction. An assumed } 3 \text { junctions } \\
\text { exist for this element. }\end{array}$ \\
\hline Temperature Effect & 0.00 & & $\begin{array}{l}\text { This is a temperature sensing device, no } \\
\text { effect }\end{array}$ \\
\hline Radiation Effect & 0 & & $\begin{array}{l}\text { Located in a low radiation environment, } \\
\text { no effect. }\end{array}$ \\
\hline Selsmic/Vibration & 0 & & $\begin{array}{l}\text { System is shut down on seismic events, } \\
\text { no impact. }\end{array}$ \\
\hline Humidity Effect & $\overline{0}$ & & No effect. \\
\hline Calibration Uncertainty & 0 & & Non calibratable device. \\
\hline Power Supply Effect & 0 & & Self powered, no effect. \\
\hline Element Accuracy & 5.90 & 7.5 & \\
\hline
\end{tabular}

The accuracy of POR32-RW-TIC-415 is as follows:

\begin{tabular}{|c|c|c|c|}
\hline \multirow[t]{3}{*}{ TIC-415 ACCURACY } & & Watlow & V4TH-CDAA-AARG \\
\hline & \multicolumn{2}{|c|}{$\begin{array}{l}\text { Common Unit Value, } \\
\text { Degrees F }\end{array}$} & Source/Reason \\
\hline & Pandom & Bias & \\
\hline Reference Uncertainty & 1.35 & & $\begin{array}{l}\text { Published data gives an accuracy of }+/- \\
0.1 \% \text { of span. The span for a type } J \\
\text { thermocouple is } 1350 \mathrm{~F} \text {, so an error of up } \\
\text { to } 1.35 \mathrm{~F} \text { can be expected. }\end{array}$ \\
\hline Temperature Effect & 6.60 & & $\begin{array}{l}\text { Accuracy is given for } 77 \mathrm{~F} \text {. The } \\
\text { maximum temperature in the panel is } \\
\text { assumed to be } 110 \mathrm{~F} \text {. The temperature } \\
\text { effect is }+/-0.2 \mathrm{~F} / \mathrm{F} \text {. }\end{array}$ \\
\hline Radiation Effect & 0 & & $\begin{array}{l}\text { The indicator is in a low radiation } \\
\text { environment. No effect. }\end{array}$ \\
\hline Seismic/Vibration & 0 & & $\begin{array}{l}\text { System is shut down on seismic events, } \\
\text { no impact. }\end{array}$ \\
\hline Humidity Effect & 0 & & Low humidity environment. No effect. \\
\hline Calibration Uncertainty & 9 & & $5 \%$ of calibration scale $(32-212 F, 180 \mathrm{~F})$ \\
\hline Power Supply Effect & 0 & & No data available, no anticipated effect. \\
\hline Element Accuracy & 11.24 & & \\
\hline
\end{tabular}


The loop accuracy as displayed on POR32-RW-TIC-415 is:

\begin{tabular}{|l|r|c|}
\hline TIC-415 Loop Accuracy & & \\
\hline & Value & Units \\
\hline Loop Accuracy & 20.20 & Degrees F \\
\hline Loop Drift & 0 & Degrees F \\
\hline Total Loop Uncertainty & 27.70 & Degrees F \\
\hline
\end{tabular}

This value of $\pm 27.7^{\circ} \mathrm{F}$ at a nominal value of $130^{\circ} \mathrm{F}$ is an error of $\pm 21.31 \%$.

The critical value is for the waste solution to remain above the temperature where precipitation of solids might occur. This point is approximately $110^{\circ} \mathrm{F}$. The setpoint will be placed above that value by a margin and all estimated errors. The control setpoint for POR32-RW-TIC-415 is established as follows:

\begin{tabular}{|l|r|l|}
\hline TIC-415 Setpoint & & \\
\hline & Value & Units \\
\hline Alarm Polnt & 110 & Degrees F \\
\hline Loop Uncertainty & 27.70 & Degrees F \\
\hline Margin & 1 & Degrees F \\
\hline Setpoint & 138.70 & Degrees F \\
\hline
\end{tabular}

\subsubsection{LOOP HT1}

\section{LOOP DESCRIPTION}

This is a simple thermostatic control loop consisting of a temperature sensing bulb buried in the insulation of the transfer line, and an associated switch TS-HT1. When the temperature exceeds a set value, the switch opens the contactor, CON-HT1 and prevents power from getting to the heat trace. When the line has cooled below the hysterisis band of the switch, the switch resets and CON-HTI closes, providing power to the heat trace.

\section{SETPOINT BASIS}

The transferred waste temperature is to range between $110^{\circ} \mathrm{F}$ and $130^{\circ}$ (Process Control Plan, HNF-4264, Rev. 0, Section 5.7) with a target temperature of $120^{\circ} \mathrm{F}$ (Process Control Plan, HNF-4264, Rev. 0, Section 2.1.2).

\section{SETPOINT VALUES}

It is critical that the temperature of the transferred waste remain above $110^{\circ} \mathrm{F}$, the estimated precipitation point of the material. Temperatures above $130^{\circ} \mathrm{F}$ are less critical.

The temperature switch is factory calibrated and the temperature bulb and switch will be disposed of with the transfer line. The error of the settings are unknown but are assumed to be within a few degrees. Therefore, a setpoint of $130^{\circ} \mathrm{F}$ is considered acceptable. 


\subsubsection{LOOP HT2}

\section{LOOP DESCRIPTION}

This is a simple thermostatic control loop consisting of a temperature sensing bulb buried in the insulation of the transfer line, and an associated switch TS-HT2. When the temperature exceeds a set value, the switch opens the contactor, CON-HT2 and prevents power from getting to the heat trace. When the line has cooled below the hysterisis band of the switch, the switch resets and CON-HT2 closes, providing power to the heat trace.

\section{SETPOINT BASIS}

The transferred waste temperature is to range between $110^{\circ} \mathrm{F}$ and $130^{\circ} \mathrm{F}$ (Process Control Plan, HNF-4264, Rev. 0, Section 5.7) with a target temperature of $120^{\circ} \mathrm{F}$ (Process Control Plan, HNF-4264, Rev. 0, Section 2.1.2).

\section{SETPOINT VALUES}

It is critical that the temperature of the transferred waste remain above $110^{\circ} \mathrm{F}$, the estimated precipitation point of the material. Temperatures above $130^{\circ} \mathrm{F}$ are less critical.

The temperature switch is factory calibrated and the temperature bulb and switch will be disposed of with the transfer line. The error of the settings are unknown but are assumed to be within a few degrees.

Therefore, a setpoint of $130^{\circ} \mathrm{F}$ is considered acceptable.

\subsection{REFERENCES:}

1) H-14-10656, Revision 0, Sheet 1

2) H-14-10657, Revision 0, Sheet 2 